OECD Health Working Papers No. 82

\title{
Mental Health Analysis Profiles (MhAPs): Sweden
}

\section{Paulfina Patana}


Organisation de Coopération et de Développement Économiques

Organisation for Economic Co-operation and Development

03-Jul-2015

DIRECTORATE FOR EMPLOYMENT, LABOUR AND SOCIAL AFFAIRS

English text only

HEALTH COMMITTEE

\section{Health Working Papers}

OECD Working Paper No. 82

MENTAL HEALTH ANALYSIS PROFILES (MhAPs)

Sweden

Pauliina Patana*

JEL Classification: I100; I120

Authorised for publication by Stefano Scarpetta, Director, Directorate for Employment, Labour and Social Affairs

* Pauliina Patana, University of Cornell, formally OECD

All Health Working Papers are now available through the OECD's Internet Website at http://www.oecd.org/els/health-systems/health-working-papers.htm

JT03379791

Complete document available on OLIS in its original format

This document and any map included herein are without prejudice to the status of or sovereignty over any territory, to the delimitation of international frontiers and boundaries and to the name of any territory, city or area. 


\title{
DIRECTORATE FOR EMPLOYMENT, LABOUR AND SOCIAL AFFAIRS
}

\author{
www.oecd.org/els
}

\section{OECD HEALTH WORKING PAPERS}

\author{
http://www.oecd.org/els/health-systems/health-working-papers.htm
}

OECD Working Papers should not be reported as representing the official views of the OECD or of its member countries. The opinions expressed and arguments employed are those of the author(s).

Working Papers describe preliminary results or research in progress by the author(s) and are published to stimulate discussion on a broad range of issues on which the OECD works. Comments on Working Papers are welcomed, and may be sent to the Directorate for Employment, Labour and Social Affairs OECD, 2 rue André-Pascal, 75775 Paris Cedex 16, France.

This series is designed to make available to a wider readership selected health studies prepared for use within the OECD. Authorship is usually collective, but principal writers are named. The papers are generally available only in their original language - English or French - with a summary in the other.

The statistical data for Israel are supplied by and under the responsibility of the relevant Israeli authorities. The use of such data by the OECD is without prejudice to the status of the Golan Heights, East Jerusalem and Israeli settlements in the West Bank under the terms of international law.

\section{Applications for permission to reproduce or translate all or part of this material should be made to:}

\author{
Head of Publications Service \\ OECD \\ 2, rue André-Pascal \\ 75775 Paris, CEDEX 16 \\ France
}

Copyright OECD 2015 


\begin{abstract}
Mental ill-health is a significant issue in Sweden, with both mild-to-moderate and severe disorders representing a significant burden of ill health. Mild and moderate mental health problems constitute the greatest number of cases, and such disorders have been on the rise over the past several decades. However, mental ill-health is also recognised as a vital national issue by Swedish authorities. Accordingly, Sweden has a relatively comprehensive approach to mental health as part of its universal health plan. Sweden was also at the forefront of such trends as deinstitutionalisation and official suicide prevention programs. Country-specific initiatives designed to tackle the most pressing psychological problems in Sweden are in place, including suicide, societal stigma and rising levels of mental problems amongst Swedish youth and workers.
\end{abstract}

\title{
RÉSUMÉ
}

La santé mentale est un problème significatif en Suède avec à la fois des troubles légers à modérés et sévères qui représentent un fardeau considérable dans le domaine de la santé. Les problèmes de santé mentale légers à modérés constituent la majeure partie des cas, et ces troubles sont en augmentation depuis plusieurs décennies. Pour autant, les autorités suédoises reconnaissent la maladie mentale comme un sujet national primordial. C'est pourquoi la Suède adopte une approche relativement globale de la santé mentale dans le cadre de son plan universel de santé. La Suède a aussi été un pays précurseur dans la désinstitutionalisation et la mise en place de programmes officiels de prévention contre le suicide. Des initiatives nationales spécifiques existent pour lutter contre les problèmes psychologiques les plus urgents, tel que le suicide, la stigmatisation sociale et l'augmentation des problèmes mentaux chez les jeunes et les travailleurs suédois. 


\section{TABLE OF CONTENTS}

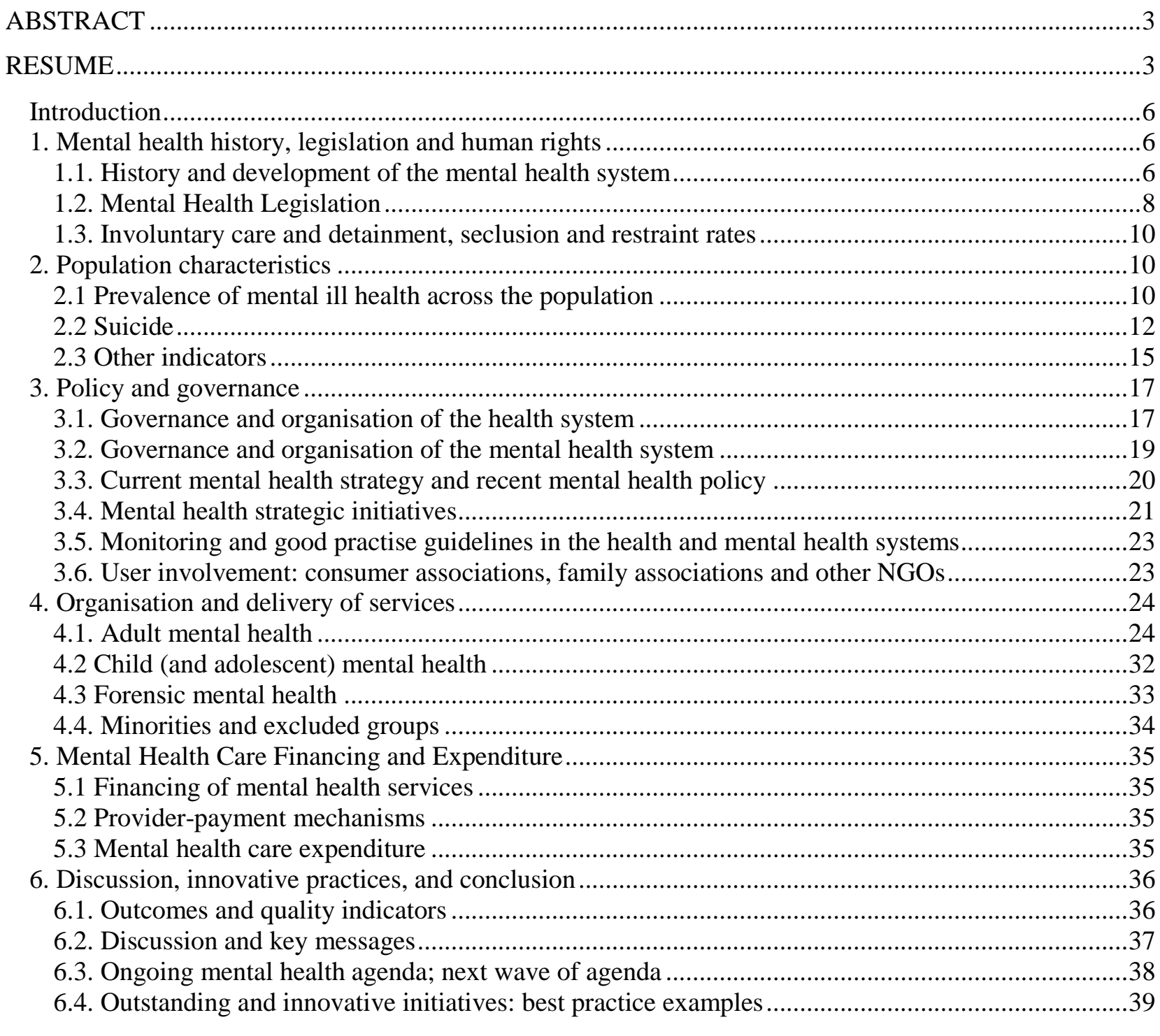




\section{Figures}

Figure 1. The prevalence of mental disorders varies with age, gender and level of education..................12

Figure 2. Suicide mortality rates per 100000 population, 2010 or latest year available .........................13

Figure 3. Change in suicide rates, 2000 and 2011 (or nearest year available .......................................14

Figure 4. Psychiatrists per 100000 population, 2000 and 2012 (or nearest year available)....................25

Figure 5. Type of provider(s) consulted for mental health problems, selected EU countries, 2010 .........27

Figure 6. Psychiatric inpatient care for men and women between 1991-2011 .....................................29

Figure 7. Primary diagnosis according to ICD-10 codes for treatment period that terminated

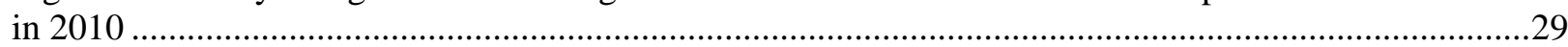

Figure 8. Psychiatric beds per 100000 population in selected OECD countries, 1995 and 2012 ............30

Figure 9. Average Length of Stay, 2000 and 2011 (or nearest year available)........................................31 


\section{Introduction}

1. Sweden's health care system is characterised by universality and decentralisation, and this system dictates that quality mental health services are to be made available to the entire population without prejudice. The actual responsibilities for health care provision are divided between three levels of government: national, regional and local. Thus, Parliament passes legislation and sets the budget for mental health initiatives, and county councils and municipalities manage mental health services and administration. While this organisational set-up allows for effective and targeted delivery of services, it also requires advanced collaboration, communication and cooperation amongst various governmental bodies and mental health care providers.

2. Sweden has made mental health policy development a priority over the past several decades. It has been at the forefront of major trends in psychiatric treatment, such as its initiation of deinstitutionalisation in the 1960s, and development of a suicide prevention programme in 1995 (updated in 2006). In 1995, the country's mental health care system underwent a major reform in order to improve quality of life for long-term psychiatric patients and emphasise community care (Silfverhielm \& KamisGould, 2000). Mental health policy has benefited from increased funding in recent years, with the most recent plan spanning 2012 to 2016. This plan specifically targets improved treatment for two groups individuals suffering from severe, long-term mental disorders and youth - while also containing measures that target all persons suffering from mental health disorders. The plan also identifies priority areas for further action: knowledge support, increased competence, quality of work and treatment, participation and influence (Regeringskansliet, 2012).

3. Recent trends in mental ill-health among the Swedish population point to improvements in some areas and deterioration in others. Deinstitutionalisation and improved social services have led to an improved quality of life amongst many people suffering from severe disorders. Meanwhile, indicators show that mental disorders (primarily mild and moderate) are on the rise in certain groups, especially among Swedish youth and in the workplace. Policy and programmes - oriented around prevention as well as treatment - have been put in place in order to address these overall areas of weakness. The Hjärnkoll anti-stigma campaign has also been implemented since 2009 to good effect by The Swedish Agency for Disability Coordination (Handisam) and The National Collaboration for Mental Health (NSPH), and is scheduled to run through 2014 (Handisam, 2011).

\section{Mental health history, legislation and human rights}

\subsection{History and development of the mental health system}

4. Similar to many other Western countries, until the 1900s mentally ill persons in Sweden were treated in separate institutions and asylums, which were regulated under the first Mental Health Act established in 1854 (Hyvönen, 2008). The development of the current structure of the Swedish health services dates back to 1862, when the county councils (responsible for the organisation and delivery of health and mental health services; see section 3.1) were established (Anell et al., 2012). While the ownership of hospitals was transferred from the national government to the county councils, mental health care remained state-run. Until the 1930s, mental institutions kept developing as a separate state system.

5. The construction of psychiatric outpatient wards in general hospitals began in the late 1930s. These outpatient wards expanded little by little to the majority of county councils. As part of general hospitals, the mental health services provided in these outpatient wards were not regulated under the Mental Health Act. Consequently, significant differences could be noted between these wards and state mental hospitals, regarding, for instance, the choice of patients, cultures of care or the length of stays. 
Outpatient wards soon surpassed the mental institutions vis-à-vis, for example, the number of personnel and the quality of care. The treatment of the severely mentally ill, however, remained concentrated in the state mental institutions. In addition to the mental hospitals and outpatient wards, a third component of mental health care also existed: separate 'nursing homes' for easy-to-treat patients were maintained by the county councils (Hyvönen, 2008)

6. A shift away from the hospital-based system, facilitated by the introduction of antipsychotic drugs, began in the 1950s and 1960s, although the number of psychiatric beds kept growing until the 1960s (Hyvönen, 2008). Having begun in the 1930s, the development of outpatient services truly took off in the 1960s, mainly through the outpatient wards in general hospitals. The 1960s also saw the establishment of first 'day-activity units' and 'day hospitals'.

7. The organisation of health services in Sweden underwent major legislative and organisational changes in the 1960s. In 1967, the county councils and their responsibilities were restructured, marking the end of the State mental hospital system (Silfverhielm \& Kamis-Gould, 2000). As part of the reform, Sweden was divided into 26 administrative units (county councils), under which operated general hospitals, primary health care units as well as psychiatric care services (Tuori et al, 2007). This reorganisation marked the end of the separate state mental hospital system.

8. In the 1970s, several county councils established strategies to develop the psychiatric care system at a regional level (Hyvönen, 2008). The aim was to abolish the system of separate mental hospitals and to move all psychiatric inpatient treatment to general hospitals (excluding nursing homes). This engagement resulted in, for instance, the reduction of psychiatric beds: between 1973 and 1980, the number of psychiatric beds in Sweden dropped by $20.6 \%$ - from 4.17 to 3.42 per 1000 population (OECD, health data, 2013a).

9. A new Health and Medical Services Act came into force in 1982. This Act integrated psychiatric care into the organisation and delivery of the general health system and thus repealed the redundant Mental Health Act (Hyvönen, 2008). A separate law was, however, established in 1984 to regulate involuntary psychiatric care.

10. A special government investigation was carried out in the early 1990s to investigate the conditions of treatment for people with long-term mental health disorders. The final report of this investigation highlighted important shortcomings in terms of the quality of care and social support for these patients (Tuori et al, 2007).

11. Following the findings of this investigation, a Mental health care reform (Psykiatrireform) was carried out in 1995 in Sweden. Changes in legislation were accompanied by increased funding for the target group in both health and social care sectors (Tuori et al, 2007). The main objective of the reform was to enable long-term psychiatric patients to live outside psychiatric institutions and nursing homes and to integrate these patients into the community. Psychiatric units and social service agencies were to increase efforts to coordinate care and support, given that social services held the responsibility for housing, daily activities and rehabilitation in the community. Adequate treatment methods were to be developed in specialised psychiatric care, and families and individuals were to be increasingly involved.

12. The number of patients in psychiatric institutions remained stable between 1994 and 2002 (Tuori et al, 2007). During the 2000s, however, a great number of remote mental hospitals were closed down and replaced by an increasing number of nursing homes and other types of housing services. By 2011, the number of psychiatric beds (per 100, 000 population) fell down to 47, well below the OECD average of 68 (OECD, 2013a). The decrease in the number of patients with schizophrenia or other severe long-term 
mental disorders as well as the transfer of patients with dementia to geriatric wards go a long way towards explaining this decline (Silfverhielm \& Kamis-Gould, 2000).

13. Since the beginning of the 2000s, concerns regarding the state of mental health services and increasing mental ill health amongst the Swedish population has been addressed by policymakers via consecutive plans and increased funding. The current plan covers the period from 2012 to 2016, and targets two groups: children and youth and people suffering from severe, long-term mental disorders (see section 3.3) (Regeringskansliet, 2012).

\subsection{Mental Health Legislation}

14. Mental health services are an integrated part of health and medical care (see section 3.1). The general provisions on the content and execution of psychiatric care are found in the Health and Medical Services Act (1982:763) and in the Health and Medical Services (Professional Activities) Act (OECD Mental health questionnaire, 2013). This Act underlines the key principles of the Swedish health care system: universal, easily accessible and good quality services. County councils shall provide good quality health and medical care, according to the needs of their residents, and promote good health in the area in general.

15. The Health and Medical Services Act also contains the general provisions on the content and execution of mental health services. Psychiatric care shall be provided to patients in need of psychiatric and/or medical treatment. These services may be provided in psychiatric clinics, via primary health care or in nursing homes by nurses. County councils shall also provide rehabilitation to their residents and ensure that patients treated under the Compulsory Psychiatric Care Act and the Forensic Psychiatric Care Act receive counselling or other personal support.

16. There are two separate, complementary laws that regulate forensic and compulsory/involuntary psychiatric care. When mental health care was integrated into other health services in 1967, compulsory treatment (including psychiatric treatment of criminal offenders) remained separately regulated by the Compulsory Mental Care Act. After revision in 1983 and following an expert commission's proposal for a new legislation in the mid-1980s, this Act was replaced by the Forensic Mental Care Act (1991:1129) and the Compulsory Mental Care Act (1991:1128). The aim of this reform was to reduce the use of coercion and to enhance legal security for the patient in psychiatric care (Bolling et al, 2009). In 2008, a new form of involuntary treatment, compulsory outpatient care, was approved by the Parliament.

17. The Compulsory Psychiatric Care Act (1991:1128) outlines the conditions under which a person may be committed to involuntary treatment. As care is not normally to be given without the individual's consent, compulsory treatment may only be ordered for patients who object to care, but are suffering from a serious psychiatric disturbance (excluding developmental disability). This care is only to be provided in instances where "due to their psychiatric condition or personal circumstances", an individual needs psychiatric treatment that will only be effective if the patient is admitted to an inpatient psychiatric care facility (Bolling et al, 2009).

18. Involuntary outpatient treatment, under special conditions, may only begin after a period of involuntary inpatient treatment. If the chief physician or psychiatrist considers that treatment may continue under outpatient status, a request for involuntary outpatient treatment may be submitted to the administrative court. Involuntary treatment may only begin if the patient has objected to it or if the patient's mental condition is "a well-founded reason to believe that the care cannot be given with his or her consent" (Bolling et al, 2009). When the need for care is assessed, it should also be taken into consideration whether the patient, as a result of his or her condition, is a danger to other people's health or safety. 
19. No minimum age for compulsory psychiatric treatment is specified. One of the requirements outlined in the Act states that, after committing a patient to involuntary inpatient care, a long-term treatment plan must be outlined. Indeed, involuntary treatment may only last for four weeks, after which the chief physician/psychiatrist must submit an application to the administrative court in order to extend the treatment for four and then six months. Compulsory treatment may not be granted for more than six months at each application.

20. The Compulsory Psychiatric Care Act also defines the criteria under which coercion may be used. In the case of immediate danger of harm to others or him/herself, the patient may be restrained with a belt for a short period of time (which may be prolonged if necessary) in the presence of health care personnel. Moreover, if the patient's behaviour is aggressive or disturbing and represents a serious problem in terms of treating other patients, he or she may be isolated for a maximum of eight hours, which may be extended for another eight hours. The National Board of Health and Welfare has made recommendations regarding the oversight and follow-up of using coercive measures.

21. The Forensic Psychiatric Care Act (1991:1129) regulates the forensic psychiatric care system in Sweden. The legislation on forensic psychiatry was revised in 1991 with the aim of reducing the number of criminal offenders in forensic psychiatric treatment, considered to be too high (Belfrage \& Fransson, 2000).

22. According to the Act, a risk assessment must be carried out while doing a forensic psychiatric examination. If there is an estimated "risk of relapse into severe criminality", a court decision must be obtained prior to the discharge from the hospital (Belfrage \& Fransson, 2000) (for further details on the Swedish forensic psychiatric system, see section 4.3).

23. As opposed to most other Western countries, the Criminal Code (1965) in Sweden determines that all offenders are considered legally responsible and culpable for the crimes they have committed. Criminal offenders that are found to be suffering from a severe mental disorder after examination are sentenced to forensic psychiatric treatment, not released due to legal insanity.

24. The Act concerning support and services for persons with certain functional impairments (1993:387) contains provisions regarding support and services for people who are, for instance, autistic, have intellectual functional impairment or other lasting physical or mental functional impairments (Tuori et al, 2007). According to the Act, these patients are entitled to certain specific forms of assistance, such as counselling, daily activities, personal assistance, housing with special services or personal companions and contacts. Given the complementary nature of this legislation, these entitlements do not "entail curtailment of assistance that the individual is entitled to according to other laws" (Tuori et al, 2007). People have the right to appeal decisions to county administrative courts. 2800 people with psychiatric disorders received support under this Act in 2003.

25. The Social Services Act (2001: 453) sets out the responsibilities of municipal social services. Municipalities are in charge of providing outreach activities for people suffering from mental disorders. In addition, municipalities shall provide appropriate housing with special services for those in need, as well as a meaningful occupation. Municipal authorities also have the responsibility to plan and coordinate assistance for these people in cooperation with other bodies and organisations involved in mental health care.

26. The Municipal Financial Responsibility Act (1995) obliges municipalities to pay for the treatment of patients who after three consecutive months of psychiatric inpatient treatment must continue being treated in a hospital. After the completion of these three months, patients are assessed and if they are judged to be unable to move into community-based independent living or sheltered housing, municipalities 
must bear the costs. The Municipal Financial Responsibility Act accompanied the Psychiatry reform in 1995 aiming to "stimulate the development of new forms of housing within the community for mentally disabled people, who have been in long-term institutional care" (Tuori et al, 2007).

\subsection{Involuntary care and detainment, seclusion and restraint rates}

27. The United Nations Committee against Torture committee expressed concerns regarding the use of coercive measures in Sweden in 2008 (Bolling et al, 2009). The committee noted that there were significant shortcomings in regards to the availability of data on the use of physical restraints or isolation. This concern has been addressed by the National Board of Health and Welfare, which has been developing a register for compulsory and forensic mental care. The lack of reliable statistical data on the use of seclusion and restraint also impedes efficient monitoring by regulatory bodies, another issue raised by the UN committee.

28. 2010 was the first year in which a comprehensive registration of involuntary commitment was recorded. According to the national patient registry, approximately $22 \%$ of the 52000 patients recorded in the national patient registry had been treated under involuntary commitment. Involuntary medication had been used in 13\% of cases, restraint in $8 \%$ and seclusion in 5\% (Lindelius 2012).

\section{Population characteristics}

\subsection{Prevalence of mental ill health across the population}

29. It has been estimated that $20 \%$ to $40 \%$ of the Swedish population suffer from some type of mental health disorder, ranging from mild to moderate to severe mental health disorders and psychoses (Stefansson, 2006). Moreover, of the 20-40\% of the population reportedly suffering from some degree of mental health disorder, psychiatric treatment has been considered necessary for $5 \%$ to $10 \%$ of the population (Regeringskansliet, 2012). However, only 3\% to $4 \%$ actually seek psychiatric care. While mental health disorders have significantly increased since the 1990s, the prevalence of severe disorders in the population has remained relatively unchanged. The increase is thus attributable to mild and moderate disorders, such as anguish and anxiety, which have become more common in all age groups with the exception of women older than 65. Between 1980 and 2003, the greatest increase of these disorders was noted among women between 16 and 34 years. The increase of mental ill health, psychiatric diagnoses and suicide attempts among children and adolescents is alarming, and therefore targeted actions have been undertaken in recent years to tackle the problem (see section 4.2).

\section{Mild to moderate mental health disorders}

30. Studies indicate that the prevalence of disease-like depression is estimated between $4 \%$ and $10 \%$ among the adult population in Sweden (Danielsson et al., 2012). The vast majority of studies also show that depression is more common among women than men. Measuring the prevalence of depression and anxiety is relatively difficult given that depression is usually experienced to varying degrees at some point in everyone's life. When depression and anxiety that require some form of treatment are measured (using standardised methods), the prevalence rates figure between $12 \%$ and $18 \%$. In this case as well, the prevalence is higher among women. However, this could in part be explained by the fact that depression among men more often leads to increased consumption of alcohol, and hence may fall into the category of substance abuse or high consumers instead.

31. A number of studies examining people over 16 years show that anxiety, agitation and sleep disorders increased in the beginning of the 2000s, especially among young people. It is, however, difficult to examine how this development has continued, as the primary source of data, the Living Conditions 
Survey conducted by Statistics Sweden, underwent methodological changes around 2006. Hence, the more recent results might not be directly comparable. In 2010, $24 \%$ of women reported suffering from anxiety and agitation and $32 \%$ had sleeping disorders. For men, the corresponding figures were $15 \%$ and $22 \%$, respectively. Women between 16 and 24 were suffering from anxiety and agitation the most (32\%), whereas sleeping disorders are more common among older women (National Board of Health and Welfare, 2012).

32. Other forms of mild to moderate disorder are also recognised. "Burnout" or "fatigue syndrome" refers to a stress-related condition linked to a certain extent to the workplace. A person suffering from burnout no longer manages to overcome everyday stressful events and experiences "emotional fatigue". It is however difficult to estimate the prevalence of burnout in the population, as, for instance, it can be hard to distinguish it from depression. Attention deficit hyperactivity disorder, on the other hand, occurs among $3 \%$ to $6 \%$ of children of school age, and boys suffer from this state 2 to 3 times more often than girls.

\section{Severe mental disorders and psychoses}

33. Every year, 1500 to 2000 people fall ill with some form of psychosis in Sweden. The lifetime risk of developing schizophrenia is around $0.8 \%$. Approximately 30000 people with schizophrenia in Sweden are in need of support from the community (Stefansson, 2006). In 2005, the prevalence of schizophrenia in the province of Stockholm was approximately $0.35 \%$ of the population (Svenska Psykiatriska Föreningen, 2009). The corresponding percentage for non-affective psychoses is $0.65 \%$ in the same area. These results indicated that the prevalence is higher in metropolitan regions compared to the whole country in 2005. 20 to 25 people out of 100000 population are diagnosed with schizophrenia in the province of Stockholm every year (Svenska Psykiatriska Föreningen, 2009). Men are hospitalised annually for psychoses (especially schizophrenia) at a slightly higher rate than women. In 2007, this number was approximately 3000 hospitalisations amongst men, as opposed to 2600 women. Data from 2011 found that $15.1 \%$ of hospitalised schizophrenia patients were re-hospitalised within 30 days of release (OECD, 2014a). Excess mortality from schizophrenia increased by 11\% from 2006 to 2011 (OECD, 2014a).

34. Less than $1 \%$ of the Swedish population develop bipolar disorder. Bipolar disorders are also found to be slightly more prevalent among women (Eliasson \& Jonsson, 2008; Cullberg, 2005). Excess mortality from bipolar disorder in Sweden increased by 21\% from 2006 to 2011, while $15.7 \%$ of patients with bipolar are readmitted to the same hospital within 30 days of release (OECD, 2014a).

35. The prevalence rate of mental disorders also varies highly between age group, gender, and educational attainment, which is shown in Figure 1 below. 


\section{DELSA/HEA/WD/HWP(2015)5}

Figure 1. The prevalence of mental disorders varies with age, gender and level of education

People with a mental disorder (either severe or moderate) by age group, gender and educational attainment, relative to the overall prevalence in the working-age population, Sweden, late 2000s

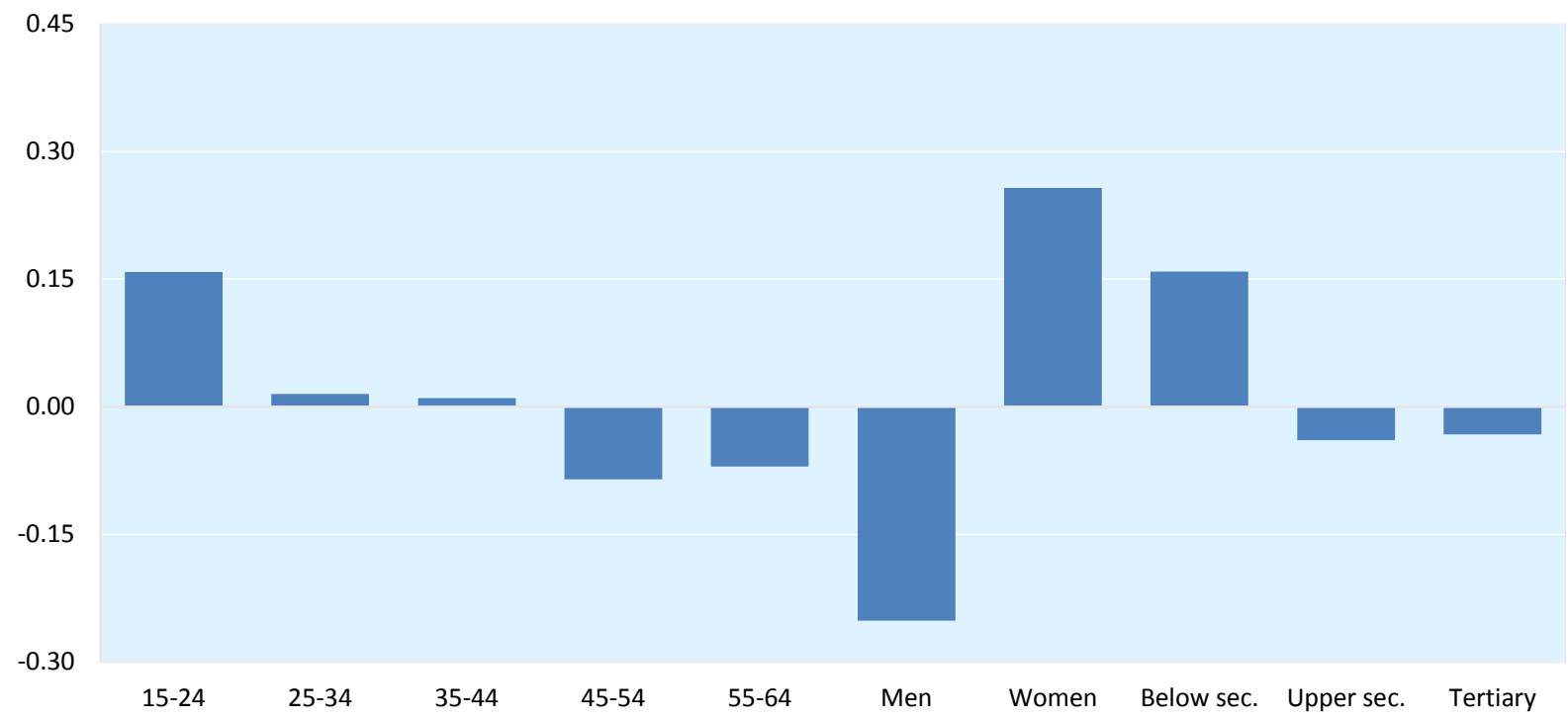

Note: Below secondary education refers to ISCED 0-2, upper secondary to ISCED 3-4 and tertiary to ISCED 5-6 (International Standard Classification of Education).

Source: OECD (2012), Sick on the Job? Myths and Realities about Mental Health at Work, Paris, OECD Publishing.

\section{Youth mental health}

36. Most mental disorders among Swedish youth are mild or moderate and are transitory. However, there has been a marked trend pointing to the deterioration of mental health among youth since the early 1990s. In its 2009 position paper on Swedish youth and mental health, the Swedish Association of Local Authorities and Regions reports that in the last three years of secondary school, 23\% of students assert that they always or usually feel stress at school and 31 per cent of the pupils at the upper-secondary schools state that they always or usually feel stressed at school (SALAR, 2009, p.12). Among this group, girls more often report feeling stress than boys. Stress, anxiety and nervousness seem to carry other health problems with them, as most young people who have these feelings also report feeling depressed. Just under half experience sleeping problems, while just over half report neck and shoulder pain. There also appears to be an association between these feelings of anxiety and nervousness and smoking and physical inactivity. Hospitalisation rates for more severe psychoses, meanwhile, have remained stable.

\subsection{Suicide}

37. Sweden exhibits suicide mortality rates slightly below the OECD average. Sweden's numbers remain relatively low when compared to the other Nordic countries, with Finland, Norway and Iceland reporting higher rates of suicide than Sweden as illustrated in Figure 2 below. 
Figure 2. Suicide mortality rates per 100000 population, 2010 or latest year available

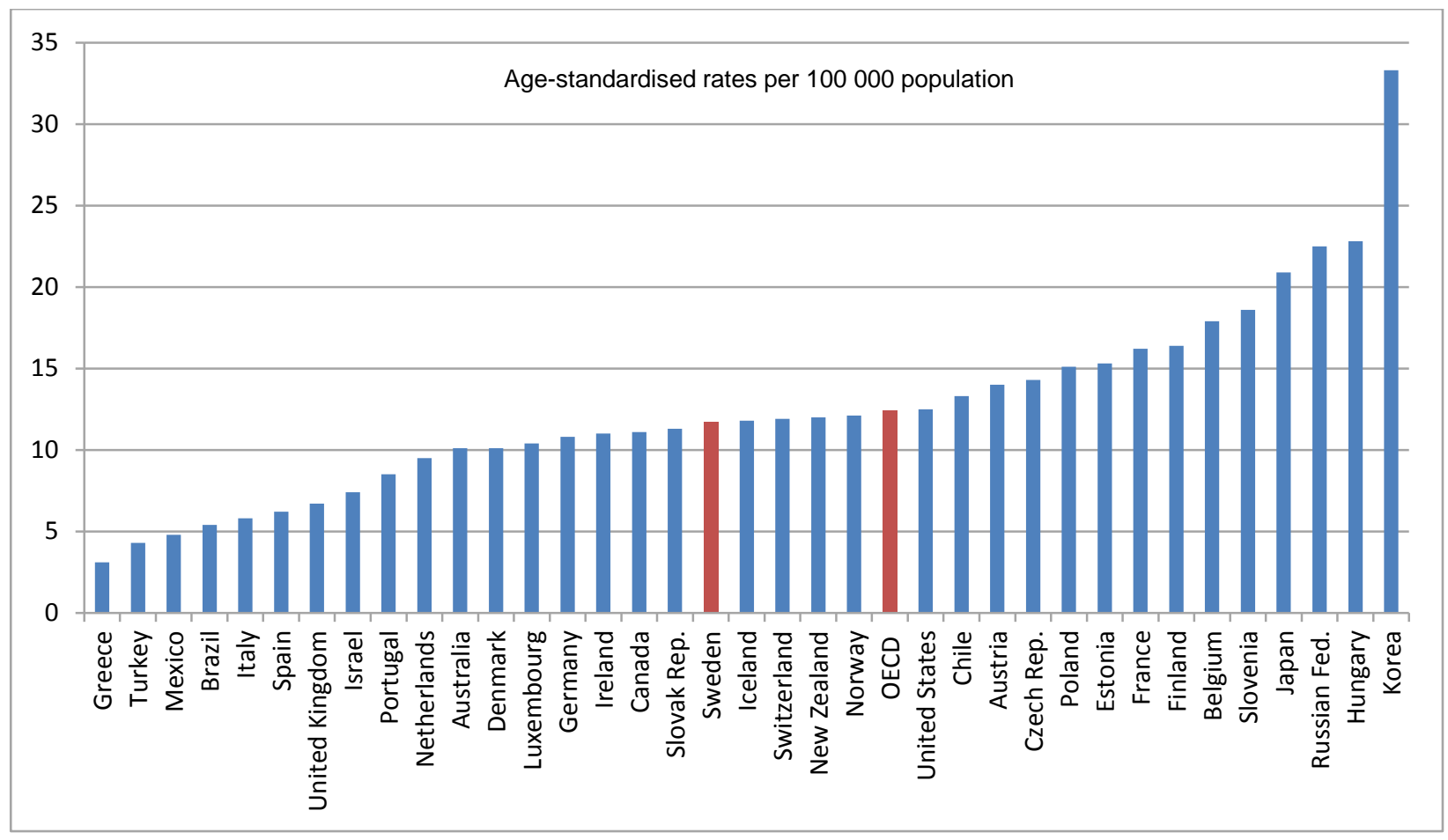

Source: OECD (2013), OECD Health Statistics 2013, OECD Publishing, Paris, www.oecd.org/health/healthdata.

38. Suicide is more common among men than women, and among older than younger people (SS, 2012). On average, 323 women and 859 men committed suicide every year between 2008 and 2010. According to the cause of death register, suicide was most common amongst 45 to 64 year-olds, followed by 25 to 44 year-olds (regardless of gender). The suicide rates in Sweden have declined between 2000 and 2011 by slightly over $5.6 \%$, which is just below OECD average of 7\% (Figure 3). However, the Annual Health report 2012 indicates that since 1990, suicides have decreased in every age group except among 1524 year-olds, where it has become somewhat more common, reflecting the overall trend of increasing mental ill health amongst youth in Sweden. On the other hand, suicide rates have declined the most among senior citizens, especially among men, and differences between the age groups have decreased. 
Figure 3. Change in suicide rates, 2000 and 2011 (or nearest year available

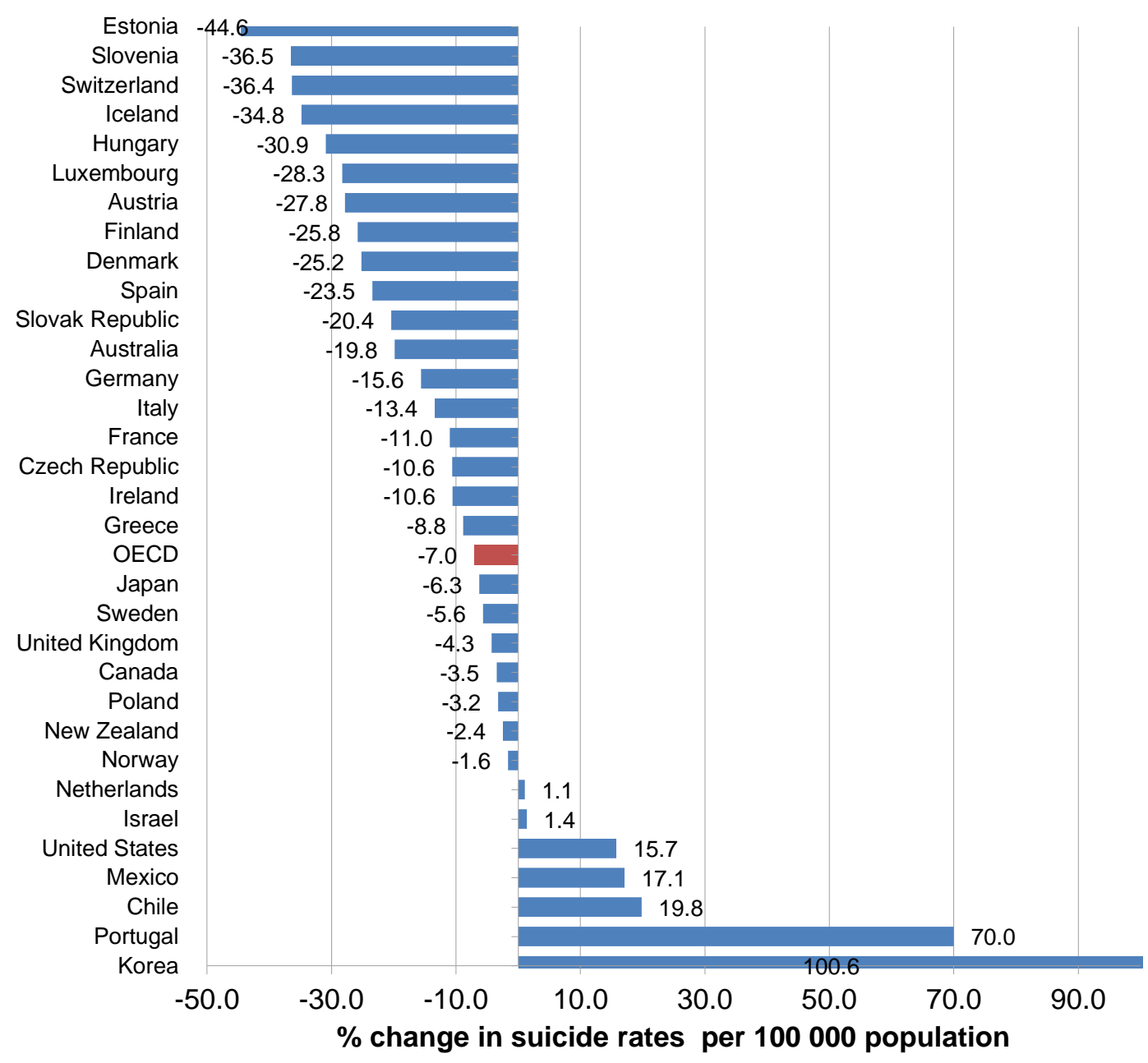

Source: OECD (2013), OECD Health Statistics 2013, OECD Publishing, Paris, www.oecd.org/health/healthdata.

39. Suicide is most frequently committed by men with a lower secondary level of education, with those holding a post-secondary degree demonstrably less prone to suicide. Differences between levels of education are more significant among men: the number of men holding a lower secondary level degree is twice as high as those with a post-secondary education. Among men between 65 and 84 years the differences remain significant but to a lesser extent. In regard to women between 65 and 84 years, the data indicates that the tendency towards suicide appears to be reversed, i.e. suicide is less common among those holding a lower secondary level degree and higher among those with a post-secondary degree (National Board of Health and Welfare, 2012).

40. A study carried out by the Swedish National Institute of Public Health in 2007 reports that $20 \%$ of women and 13\% of men (amongst 16 to 29 -year-olds) have had suicidal thoughts at some point in their lives. Suicide attempts are far less frequent but still occur at a disquieting level, with $6 \%$ of women and $4 \%$ of men attempting suicide in their lifetime. Although the rate of hospitalisation for suicide attempts and other self-destructive behaviour had been on the rise amongst 16 to 24 -year-olds from the early 1990s until 2007, there has been a noticeable decrease in these numbers since. Young women nonetheless are hospitalised for suicide attempts at twice the rate of young men (300 young women per 100000 inhabitants, as opposed to 150 young men) (Socialstyrelsen, 2007). 
41. Since the early 1990s, Sweden has been a proactive actor in the field of suicide prevention. This is currently manifested in the form of The National Programme for Suicide Prevention, which was ratified by the Swedish Parliament in 2008 and aims to reduce the nation's number of suicides and suicide attempts (see Section 4.5).

\subsection{Other indicators}

\section{Work disability and mental health disorders}

42. Mental disorders represent the most common work-related health problem in Sweden. In terms of mild to moderate problems, stress is a significant contributor to this decline in wellbeing, and the proportion of people reporting stress problems has been observed to rise and fall at rates that correspond to employment levels since the mid-1990s. An increasing number of individuals have reported that work is hectic and mentally taxing since the early 1980s, and this deterioration of mental wellbeing has been seen to be associated with a rise in the number of people suffering from other mental and physical ailments such as anxiety, nervousness, constant fatigue, sleeping problems and neck and shoulder pain.

43. Although this rising trend shifted into decline beginning in 2001, improvement was not observed amongst young people, who continued to report such conditions in increasing numbers. The 2012 Swedish National Public Health report has noted that the number of approved new claims has stalled and even fallen amongst people 30 to 64 years old, but has continued to rise amongst those up to 29 years old. The study suggests that a reason for the negative trends that have been observed over the past several decades may correspond to an environmental shift in which "the balance between healthy and unhealthy factors impacting the actively employed has tilted towards less favourable conditions" (Danielsson et al., 2012).

44. The employment rate of people with especially severe mental health disorders is approximately half that of people with no disorder. Whereas the employment rate for people not experiencing any type of mental health disorder was nearly $80 \%$, for those suffering from a moderate disorder that number dropped to approximately $75 \%$. The percentage plunged even further for individuals experiencing severe mental health disorders, to a 45\% employment rate (OECD, 2012a). A difference in the level of income can also be noted. The average income of people with a moderate mental health disorder is slightly below $90 \%$ of the average income of the total population. The figure for people suffering from severe mental health disorder is lower, at around $85 \%$. As a comparison, however, Australia and the United States exhibit figures below 70\% (OECD, 2012a). Moreover, disability benefit claims have also considerably increased between the mid-1990s and 2009. Indeed, whilst newly granted disability benefits for people suffering from a mental health condition accounted for $20 \%$ of all disability benefit grants in the mid-1990s, in 2009 their proportion had doubled to slightly over $40 \%$. This number, however, is not entirely out of sync with other Nordic countries. In Denmark, disability benefits due to mental health disorders accounted for approximately $45 \%$ of the total, while the 2009 rate remained a relatively low $25 \%$ in Norway (OECD, 2012a).

45. Elements within the work market that restrict the hiring of individuals with mental disorders are both attitudinal and institutional. A significant stigma exists concerning mental ill-health that discourages employers from hiring people with mental problems. A lack of knowledge on the part of employers leads to concerns regarding the work effectiveness of individuals with mental disorders as well as concerns about consequences their presence may have on other workers. In an effort to address this issue, societally in general and professionally in particular, Sweden has launched the Hjärnkoll anti-stigma campaign. This effort has had a quantifiable, overall positive impact on Swedish views of mental disorders (see 4.5).

46. In addition, it is worth noting that Swedish hiring practice features a seniority, or "last in-first out" dismissal rule under the Swedish Employment Protection Act (EPA, Lagen om anställningsskydd, 
SFS 1982:80, 22 §). It is possible to make derogations from this rule, however, by means of collective agreements, which are used in practice. It should also be noted that there is an additional paragraph specifying that an employee who has a reduced working capacity and who has, therefore, been given special duties by the employer, shall be given priority for continued work, notwithstanding the rules on priority (where such can be accomplished without serious inconvenience to the employer). Furthermore, in order to make a legal dismissal in Sweden, there must be objective grounds for such an action beyond the existence of an illness. Only if the affected individual is unable to produce any substantial work, and cannot be reassigned to a more suitable position by the employer, is there just cause for dismissal. The Employment Protection Act covers all employees and contains no derogations for disabled persons. However, there is special legislation regarding discrimination of disabled employees.

47. Strict employment protection legislation has been shown to reduce employment and participation rates, especially in the cases of individuals who are already prone to entry problems, such as people with mental health issues (OECD, 2013b). Furthermore, such employment protection legislation has the potential to lock people into their current positions and reduce job mobility. This can be especially problematic for those with mental health problems, as they may be particularly reluctant to leave a position for fear of difficulty in securing a new one, even though a change of job may help address the root cause of their illness. Such individuals are also likely to be disadvantaged in such a system due to their increased likelihood to be on temporary contracts and tendency to change jobs more frequently. In Sweden, however, fixed term employment is considered an important stepping-stone into working life for vulnerable groups, although open-ended contracts remain the rule.

\section{Youth and mental health in the workplace}

48. Mental health issues also tend to arise among Swedish youth as they transition out of the education system and into adult employment. This is especially true for young people who are neither employed, in the education system or in training, a situation that places them at a disadvantage in comparison to their peers. Among this group in Sweden, young men develop a mental disorder at twice the average rate, and young women are even more likely to suffer from depression or anxiety (OECD, 2013b). Furthermore, there is a high rate of early withdrawal from the labour market amongst youth in Sweden. Over a third of new disability claims currently stem from young people (aged 15-24) (OECD, 2013b).

49. There is evidence that seems to point to the conclusion that mental health among Swedish youth is in a state of decline, indicated by a doubling or more of rates of depression and anxiety, dejection, sleep disorders and self-harm. (Royal Swedish Academy of Sciences, 2010; Ahrén, 2010). A 2013 study completed by the Swedish National Board of Health and Welfare (Socialstyrelsen) found that people aged 15 to 24 were most likely to be admitted to hospital for self-harm. Between 2009 and 2011, an annual average of 275.1 women per 100000 and 115.3 men per 100000 were hospitalised due to self-injury; these numbers dropped to 132.6 women and 91.3 men amongst 25- to 44-year-olds, and continued to fall to 89.8 women and 70.7 men amongst 45- to 64-year-olds (National Board of Health and Welfare, 2013). Furthermore, hospitalisation among young adults has risen markedly due to depression and anxiety, and the number of those being treated as outpatients has risen dramatically (see section 4.1.iii).

50. Reported feelings of anxiousness, nervousness and anxiety have increased three-fold among upper-secondary school students as well as among individuals who have recently moved into adult status. Most young people who report feeling anxious or stress also report tendencies towards depression, nearly half also have sleeping problems and over half have neck and shoulder pain as well.

51. However, epidemiological and clinical empirical evidence paints a different picture, in which mental illness rates in real terms are not in fact undergoing such an alarming growth. According to the recent OECD report entitled Sick on the Job? (2012a), this seeming contradiction could in fact be due in 
part to reduced levels of stigma and discrimination against individuals who report mental ill-health, as well as greater public awareness regarding psychological problems. Such a shift in viewpoint may account for a larger number of cases being identified and disclosed, rather than an actual rise in mental health problems of such dramatic proportion.

52. In any case, it is recommended that a disability benefit scheme be developed for individuals under 30 that emphasises vocational rehabilitation and replaces disability benefit entitlement for youth for prolonged schooling with a study grant. In order to reduce the tendency of early dependence on disability benefits, it is suggested that labour policies and measures should be put in place that boost labour demand and encourage hiring of young people (OECD, 2013b).

\section{Policy and governance}

\subsection{Governance and organisation of the health system}

53. The health care system in Sweden, mainly financed through general taxation, is highly decentralised and characterised by universal coverage and equal access to services. The Health and Medical Services Act (1982) lays down the regulation regarding the provision and organisation of health and medical services (Anell et al, 2012).

54. There are three political and administrative levels regarding health and medical services; national, regional and local. The State, through the Ministry of Health and Social Affairs and eight central government agencies ${ }^{1}$, is in charge of general health policy, legislation, supervision and evaluation of health care services. The Ministry of Health and Social Affairs is charged with the implementation of Riksdag (Swedish Parliament) and Government objectives. As such, this body is in charge of monitoring and analysing health and medical care, drafting legislation and guidelines, advancing policy issues and negotiating with responsible county council and municipal bodies to facilitate health and medical care. Mental care falls under this umbrella responsibility.

55. County councils and municipalities, which are represented by the Swedish Association of Local Authorities and Regions (SALAR), are responsible for the organisation, financing and provision of primary and secondary health care services. The Health and Medical Services Act underlines that services must be provided according to the needs of their citizens, but gives the regional and local authorities considerable freedom in choosing how to organise these services (Anell et al, 2012).

56. At a regional level, the 17 councils and 4 regional bodies are in charge of financing and providing health care services to their residents. The majority of health and medical services fall under the responsibility of county councils, whose representatives are elected by the residents every four years. County councils are obliged to provide health and medical services of good quality as well as to promote good health in the population. Primary care is delivered through 1100 (public or private) primary care units in the country. In most of the counties, it is possible to bypass primary care and access specialist services directly (there is no gate-keeping). There are significant variations regarding the proportion of private units between the counties. For instance, Stockholm, Halland and Västmanland private units account for around half of all units, whereas in other county councils there are only a few.

57. There are approximately 70 hospitals providing specialised care. In addition, seven regional (university) hospitals provide highly specialised care. Due to the counties' relatively small catchment areas

1 The National Board of Health and Welfare, the HSAN, the Swedish Council on Technology Assessment in Health Care, the MPA, the TLV, the Swedish Agency for Health and Care Services Analysis, the Swedish Social Insurance Agency and the National Institute for Public Health 
and to enhance cooperation regarding tertiary medical care, the counties are divided into 6 medical care regions, each covering a population of approximately 1 million people. The vast majority of hospitals are publicly owned (by the county councils) and there are only six private hospitals (of which three are forprofit) in Sweden.

58. At a local level, municipalities are in charge of social welfare services, which include for instance financial assistance, childcare and school health care. Municipalities also hold the responsibility of providing and organising social and housing services for elderly people, those with disabilities and for long-term psychiatric patients (WHO, 2012). The elderly's right to receive public services and support is laid down in the Social Services Act (1980). In addition to the Social Services Act, the Act Concerning Support for People with Certain Functional Impairments (1993) also obliges municipalities to provide support for people with disabilities. There are both public and private housing service providers (nursing homes and home-based services) (Anell et al, 2012).

59. Trade unions and professional organisations traditionally play an important role in Sweden, and consequently the majority of people working in health services are members of professional unions. Approximately 110000 health professionals, including registered nurses, midwives, biomedical scientists and radiographers are represented by the Swedish Association of Health Professionals (Vårdförbundet). The Swedish Medical Association (Sverige's Läkarförbund), on the other hand, represented approximately 90\% of physicians (43 000 of Sweden's doctors) in 2011 (Anell et al, 2012).

\section{Occupational health services}

60. The Work Environment Act was passed by the Swedish Parliament in 1977 (last updated 2011). It outlines the official regulations designed to ensure a safe working environment, including the protection of employee mental health. Specifically, the Act states that "working conditions shall be adapted to people's differing physical and mental aptitudes... Technology, work organisation and job content shall be designed in such a way that the employee is not subjected to physical or mental strains which can lead to ill-health or accidents."(Swedish Work Environment Authority, 2014). Overall wellbeing and satisfaction at work is further addressed, as "Monotony, stress and isolation at work are to be avoided by adapting working conditions to human aptitudes. [...] The aim is for work to be found a meaningful, rewarding aspect of life." Chapter 3, Section 2c of the Work Environment Act declares that the employer is responsible for making occupational health services available, appropriate to the working conditions and including rehabilitation treatment. The Swedish Work Environment Authority and regional Labour Inspectorates are in place to enforce compliance with the Act.

61. However, OHS are not strictly mandatory. Since public financial support ceased in 1992, the purchase of these services is left to the employer's discretion (although since 2010 the Swedish Government offers financial support if OHS's provide measures to promote return to work for sick-listed employees). According to a recent OECD publication (2013b) concerning mental health and work in Sweden, approximately three in four Swedish employees have access to OHS, with availability of services ranging widely depending on what is purchased by the employer. Concerning mental health, evidence shows that confidential counselling and conflict resolution procedures are used relatively frequently in Swedish workplaces in comparison to other European countries. As anecdotal evidence suggests that individuals with mental health issues are more likely to use sickness benefits due to conflict at work, which requires more personalised support, this figure appears to suggest a positive approach to mental health in the workplace.

62. On the other hand, there is evidence that mental health concerns are not thoroughly addressed. Smaller organisations have difficulty in implementing risk assessments for potential psychological risks (although the current framework outlined by the Work Environment Act provides a useful starting point 
that could be further developed in these instances). Furthermore, OHS are under-utilised in terms of effective support for employees struggling with psychological disorders. Of the assessments carried out by OHS in Sweden in 2010, only 14\% were related to workload or stress (compared to 23\% concerning work posture and/or heavy work). Moreover, despite the recent initiative to fund OHS where efforts to monitor sickness absences are in place, fewer than 5\% of the assessments looked into sickness absence issues (OECD, 2013b).

\section{Disability benefits}

63. Individuals unable to work due to mental illness are entitled to sickness or disability benefits. These are applied under a sickness benefit scheme for people suffering from a temporary illness, a disability benefit scheme (Activity Compensation) for youth 19 to 29 years old with reduced work capacity, or a disability benefit scheme (Sickness Compensation) for adults 30 years old or more with permanent impairments.

64. Sickness benefits amount to approximately $80 \%$ of annual income for the first year, which is thereafter reduced to approximately $75 \%$. These benefits can be received for a total of 914 continuous days. There are exceptions to the time limits. For example, those with a very serious illness can receive sickness benefit at around 80 per cent with no time limit. The cost is borne by the employer for the first fourteen days, with financial responsibility shifted to the Swedish Social Insurance Agency (SSIA) thereafter. The first day is a waiting day with no compensation. Young adults suffering from a condition that reduces their work capacity by at least a quarter for a minimum of one year are entitled to Activity Compensation, receivable for a maximum of three years at a time, after which a reassessment is required. The amount is based either on $64 \%$ of the average of the three highest previous gross yearly incomes within a certain time frame, or a fixed guaranteed amount based on the individual's age (between 19 and 29), whatever is higher (the maximum guarantee amount being SEK 104340 per year in 2014. Sickness Compensation is awarded to adults 30 years old or more on much the same basis, except they are permanent disability benefits (as opposed to the temporary three-year benefit as under Activity Compensation).

65. Mental disorders represent a significant burden within the context of this system. According to Sweden's 2012 National Public Health Report, mental disorders - including such afflictions as depression, schizophrenia, chronic fatigue syndrome, mental disabilities, personality disorders and drug abuse combined with musculoskeletal disorders account for $76 \%$ of all new disability claims amongst women, and 65\% of similar claims amongst men in 2006 (National Board of Health and Welfare, 2012). The most commonly diagnosed issues amongst these conditions are depression, adjustment disorders, reactions to stress and anxiety disorders.

\subsection{Governance and organisation of the mental health system}

66. Mental health services are an integrated part of health services and are regulated under the same legislation. The care system for people with mental health disorders is supported at all three political levels.

67. The counties and regions are responsible for organising and providing primary and secondary mental health services, including primary care provided by GP and their medical professionals working in primary care settings. Mild to moderate mental health problems can be discussed in primary care with a GP, psychologist or therapist. When dealing with patients experiencing severe mental health disorders, they are referred to specialist psychiatric care provided in hospitals. The proportion of privately provided specialised psychiatric care was approximately 7\% in 2010 (SALAR 2011a; Anell et al 2012). Specialist psychiatric care includes both inpatient and outpatient care for people (including children and adolescents) 
with psychiatric problems or mental impairment, and treatment of mental disorders overlapping with substance abuse problems.

68. In 1995, in the context of the Psychiatric Care Reform, municipalities were given the responsibility of care for psychiatric patients "regarded as fully medically treated". This shift of responsibility from countries to municipalities was accompanied by the downsizing of psychiatric hospital beds already taking place in the 1990s, aiming to reduce inpatient care and facilitate the adoption of a more 'community-care-based' approach.

69. Mental health services in Sweden have undergone significant changes over the past 50 years (see section 1.1), with a clear emphasis on developing outpatient care. The Swedish Disability Act and the Act Concerning Support and Services for People with Certain Functional Impairments (1993) include people with mental health problems and consequently entitle them to 'a list of specific forms of assistance such as counselling and support, personal assistance, housing with special services, access to contact people and to companions' (Anell et al, 2012).

70. Moreover, county councils have the responsibility of ensuring that individuals falling under the jurisdiction of the Compulsory Mental Care Act and Forensic Mental Care Act receive the necessary counselling and other personal support.

\subsection{Current mental health strategy and recent mental health policy}

71. After the psychiatric care reform in 1995, the shortcomings of mental health services in Sweden were once again brought to the fore in 2003, when five homicides were committed against strangers by people with a history of mental health disorders within a few months of each other. Out of these, the most widely covered by the media was without a doubt the killing of Anna Lindh, the Swedish Minister for Foreign Affairs. The fact that these homicides were committed by people who had been in contact with mental health services brought new attention to the longstanding complaints expressed by mental health professionals, service users as well as the public concerning mental health policy in Sweden.

72. As a response, the Government engaged in developing a new approach by appointing a commission called the National Psychiatric Services Commission (NPSC, Nationell psykiatrisamordning). This Commission appointed a small number of renowned professionals specialised in psychiatry to identify and analyse the problems affecting mental health services, including forensic psychiatry. The focus of this group was on people suffering from mental health disorders with substance abuse comorbidity (while dementia, intellectual disability and substance abuse alone were excluded from the scope of the analysis). With 90 million euros of funding, the commission was given three years to "initiate and support project development at all levels (medical treatment, service improvement, housing projects, legislative and organisational improvements) and to propose measures needed in order to permanently raise the standard of mental health services." Special attention was paid to improving the coordination between mental health and social services.

73. Two final reports were published in 2006. While the first one covers 'the care and treatment of mentally disordered offenders' (SOU 2006:91), the other concentrates on developing psychiatry in general (SOU 2006:100). The second report, focusing on the needs for development in the field of psychiatry, made several propositions. For instance, it suggested that government funds and "supports local counties to establish housing sensitive to the needs of various subgroups of people with mental health disorders". Moreover, government funding was also to be granted to facilitate "the development of organised daily activities over and above rehabilitation programmes". Indeed, many recommendations depended on increased government spending on psychiatry. The report also outlined other areas of improvement, such 
as national planning and coordination, setting of national standards in general and forensic psychiatry, as well as a monitoring system.

74. In May 2012, Sweden committed to an extended action plan for mental illness that would span the period from 2012 to 2016. During this period, the Swedish Government, working in conjunction with the Swedish Association of Local Authorities and Regions (SALAR), will devote SEK 870 million each year to prevent mental illness and improve health and social care for individuals already in the system. Indeed, one of the key elements of the current mental health plan is the broad agreement reached with SALAR: long-term commitment to tackling mental ill health will be ensured through economic incentives provided to local authorities. The plan targets two groups: children and youth, and people suffering from significant psychiatric problems. Increasing employment amongst individuals with a mental disorder is also listed as a priority. The Swedish Agency for Health and Care Services Analysis will be following the action plan and evaluating its effects. A final report will be presented in 2017.

75. Furthermore, as part of the Nordic Council, Sweden is taking part in a regional effort to improve mental health throughout the Nordic countries through joint research and exchange of information. For example, Sweden was involved in the launch of the third Nordic Council's health indicator project, which served to amass a comprehensive set of mental health quality indicators across the Nordic countries. In 2011, a report was prepared to allow for the comparison of Nordic countries, specifically including information on indicators that could be used as a basis for the monitoring of mental health services. A number of areas were incorporated, including measurement of generic indicators mental health services, compulsive measures, electroconvulsive therapy, levels of schizophrenia, hospitalisation for depression, bipolar disorder, attention deficit hyperactivity disorder, and patient/family member-rated quality of services.. A multilateral Expert Group was also formed to explore areas of common problems and challenges facing all Nordic countries in the mental health field. The goal of such efforts is to enable the Nordic countries to cooperate at the highest level in order to establish most effective policy avenues (Nordic Council of Ministers, 2011).

\subsection{Mental health strategic initiatives}

\section{Suicide prevention}

76. Sweden initiated the National Council for Suicide Prevention in 1993, making it one of the first countries worldwide to establish a comprehensive national strategy for suicide prevention. In 1994, a parliamentary decision led to the creation of a National Centre for Suicide Research and Prevention of Mental Ill-Health (NASP). NASP's first national network for suicide prevention coordination was initiated in 1997, which was then organised into six regional networks (corresponding to Sweden's health care regions). This network coordinates cooperation between involved actors - including health care providers, social services, schools, churches and NGOs - and aims to facilitate suicide prevention efforts and integrate national public health work on a local level.

77. The National Programme for Suicide Prevention (commissioned by the Swedish government in 2005) was ratified by the Swedish Parliament in 2008 as an initiative that aims to reduce the number of suicides in Sweden. It was produced as a collaborative effort between the Swedish Institute of Public Health (which produced guidelines for the population level) and the Swedish National Board of Health and Welfare (which produced guidelines for the individual level) with support from NASP. The government provides the funding for the Programme's ongoing initiatives.

78. The Programme is oriented around nine strategies designed to target suicide and suicide attempts in Sweden: focus on disadvantaged groups; reduction of alcohol consumption; reduction of the availability of means of suicide; education of gatekeepers concerning effective management of individuals with suicide 
risks; support for medical, psychological and psychosocial suicide prevention services; dissemination of knowledge about evidence-based methods to reduce suicide; improved competence among relevant personnel regarding suicidal individuals; analysis of suicide cases occurring within the healthcare system and within 28 days of discharge (Lex Maria); and NGO support.

79. In practice, the programme aims to provide a comprehensive initiative using process-oriented and epidemiological measures that can be continuously evaluated. For example, the "Lex Maria" component of the Programme, aiming to report all suicides occurring while in the healthcare system or within 28 days of exiting it, permits authorities to identify areas where treatment can be improved when dealing with suicidal patients. All such reports are registered within a database with the National Board of Health and Welfare, which allows for a nationally drawn systematic analysis. This comprehensive analysis allows for the formulation of targeted proposals for improvement, such as the development of better suicide risk assessment routines, improved communication within and between units, and investment in psychiatric health care staff training directed specifically at the care for suicidal patients. Given that approximately $20 \%$ of all suicides in Sweden are committed by psychiatric inpatients (Hadlaczky, 2012), this regulation represents a concrete effort to reduce suicides amongst this high-risk group.

80. NASP reports a $13 \%$ decrease in suicide levels amongst the general population of people 15 years old or older since 2005 (falling from 20.1 suicides per 100000 individuals in 2005 to 17.5 in 2011) (NASP, 2012).

\section{Anti-stigma initiative - Hjärnkoll}

81. The Swedish Government initiated the Hjärnkoll anti-stigma initiative in 2009, scheduled to run through 2014 (Handisam, 2011). It is handled by the Swedish Agency for Disability Policy Coordination and the National Collaboration for Improved Mental Health. The goal is to raise awareness among the general population of the widespread nature of mental illness and to reduce the discrimination that individuals with mental illness often face.

82. According to the Hjärnkoll initiative, one in four people in Sweden experiences a mental health condition, while three in four have experience or know someone with a mental health condition. Mental illness is the most common reason listed for long-term sick leave in the workplace. Despite this prevalence, mental illness is still subject to significant stigma. Hjärnkoll's stated mission is to raise awareness, change public attitudes about mental illness and end discrimination. In concrete terms, the programme aims to create a 5\% positive shift in public attitudes concerning mental health problems, recruit 10000 individuals and 200 employers as supporters of the campaign and to increase media watch regarding stories with people with direct experience in living with mental health conditions.

83. In practice, the programme's approach emphasises personal experience and the importance of the role of employers. For example, Hjärnkoll utilises mental health ambassadors to talk to the media and other audiences (including workplace conferences, seminars or meetings) about their experiences of living productive lives despite their mental health conditions. The programme provides support on how to reach out to media and employers. In addition, to address the lack of understanding that exists among employers regarding the employment of people with mental health issues, the initiative gives practical advice on the support and management of individuals with mental health problems in the workplace. In furtherance of this, Hjärnkoll has drawn upon the English SHIFT initiative (a similar initiative that was aimed at the reduction of stigma and discrimination surrounding mental ill-health in England), translated the programme's resource guide for managers into Swedish and adapted it to the local context.

84. A comparative study conducted on the results of the campaign between 2009 and 2011 has found that measurable improvements in public attitudes have been noted during this period. Opinion changes 
have been reported among every second person who did not want a person with a mental illness as a neighbour, among every third person with a negative response to the idea that people with mental conditions lived in their neighbourhood, and among every sixth person who had initially not wanted a person with a mental health condition as a neighbour. Media analysis comparing April-June 2010 with the same period in 2011 has shown a 64\% increase in media stories that discuss living with mental health.

85. A 2014 controlled study conducted to examine the effectiveness of an anti-stigma intervention in a basic police officer training programme found the intervention, based on the Hjärnkoll program, proved to be effective in changing attitudes, mental health literacy and intentional behaviour (Hansson and Markström, 2014).

\subsection{Monitoring and good practise guidelines in the health and mental health systems}

86. The National Board of Health and Welfare is in charge of developing a national system of monitoring the field of psychiatry and guidelines to support policymakers as they carry out decisions regarding the allocation of resources within Health and Medical Care and Social Services (Socialstylrelsen, 2014). The aim of national guidelines is to support priority setting in the county councils, contribute to the efficient use of health care resources, distributed according to need, and governed by systematic and transparent priority setting. In the field of psychiatry, guidelines have been developed for psychosocial interventions for schizophrenia and schizophrenia type conditions; for care in cases of depression; anxiety disorders and dementia.

87. The guidelines aim to support: 'decisions on resource allocation within and between different groups and operations; decisions about operational planning; decisions about organisation of the different activities; decisions on regional and local medical care programmes and individual decisions made by e.g. doctors, case officers within social services or dentists in the consultations with the patients or users' (National Board of Health and Welfare). Decisions on guideline areas are made on the basis of the significant prevalence of chronic illness which consequently represents a high cost to the society and of demand expressed by policymakers and service providers.

88. The guidelines for the care of depression and anxiety disorders pinpoint the need of easily accessible and effective care within the front-line (e.g. primary care) and a selection of several effective treatment options throughout the entire care. In order to achieve an offer of effective treatment options Health and Medical Care need to increase access to psychological treatment, primarily CBT. In the case of schizophrenia guidelines for psychosocial interventions recommendations concerning coordinated measures (Assertive Community Treatment - ACT model), family interventions, psychological treatment and vocational rehabilitation are those with the greatest efficacy.

89. The National Board of Health and Welfare also performs independent national evaluation of health and social care services and publishes reports on open comparisons of the quality and efficiency of the health and social care on the basis of good care. A substantial part of this work is to better describe care for people suffering from mental health disorders, which is essential for all efforts to enhance and develop work in this field.

\subsection{User involvement: consumer associations, family associations and other NGOs}

90. User or consumer groups in the area of mental health exist in Sweden but they are not directly involved in developing national strategies or legislation (OECD Mental health questionnaire, 2013). However, the National Collaboration for Mental Health (NSPH) is a notable and influential actor in the field of mental health care in Sweden. 
91. Based in Stockholm, NSPH is an umbrella organisation that brings together national patient organisations (or organisations involved with users or relatives). Although it does not directly develop national policy, its aim is to promote the development of improved psychiatric treatment via the enabling of relevant authorities to "benefit from the experiences and empowerment advocated through user participation from patients, users and relations" (NSPH). They also work to support patient voices, improve accessibility, develop mental illness prevention, spread information and influence public opinion, provide support and resources to interested organisations and cooperate with authorities and other mental health organisations on a national level.

92. NSPH counts eight local and regional networks, which carry out work on a more localised level. As a whole, it receives an annual allocation from the Ministry of Health and Social Affairs of EUR 375 000, which allows it to maintain its offices, assemble delegates 4 to 5 times per year, and hold work group meetings 8 to 10 times annually. These work group committees meet to discuss the advancement of NSPH goals within the Swedish health care community and society.

93. Currently, NSPH is active in the 2012-2016 action plan, participating in both the strategy and reference groups helping to shape the initiative's overall direction. In 2013, NSPH received financial support from the Swedish government to, among other things, formulate strategies aimed at strenghening and enhancing the influence of user organisations on national, regional and local levels, as well as for the individual when meeting with health care providers. NSPH also plays a role in the development of improved quality monitoring by sharing the experiences of patients and relatives in their dealings with mental health care services. Finally, NSPH is currently collaborating with the Swedish Agency for Disability Policy Coordination (Handisam) to run the Hjärnkoll anti-stigma initiative, which will run through 2014 (see 3.4.2).

\section{Organisation and delivery of services}

\subsection{Adult mental health}

94. Health and Medical services have an obligation to provide information to the National Board of Health and Welfare's patient register. Whilst in general this register is of high quality, in terms of psychiatric services the quality varies. In particular, there are shortcomings in the reporting of specialised psychiatric outpatient services while the quality is higher for psychiatric inpatient care (National Board of Health and Welfare, 2012).

95. The National Board of Health and Welfare has increased efforts to improve the quality of reporting to the patient register, such as getting private mental health care providers to report in the register or the possibility to include data from primary care, visits to a psychologist or curators to be included. At a national level, only doctor's appointments and specialised psychiatric outpatient care can currently be included in the patient register (National Board of Health and Welfare, 2012).

\section{1.i. Human resources and education}

96. The number of psychiatrists in Sweden is well above the OECD average as illustrated in the Figure 4 below. Since 2000, this number has risen slightly, from 19 to 21 (per 100000 population) in 2012. Even though Sweden exhibits a high number of psychiatrists compared to other OECD countries, it is nonetheless lower than in one other Nordic countries, Iceland and only slightly higher than in Norway and Finland (Figure 4) (OECD, 2012b). 
Figure 4. Psychiatrists per 100000 population, 2000 and 2012 (or nearest year available)

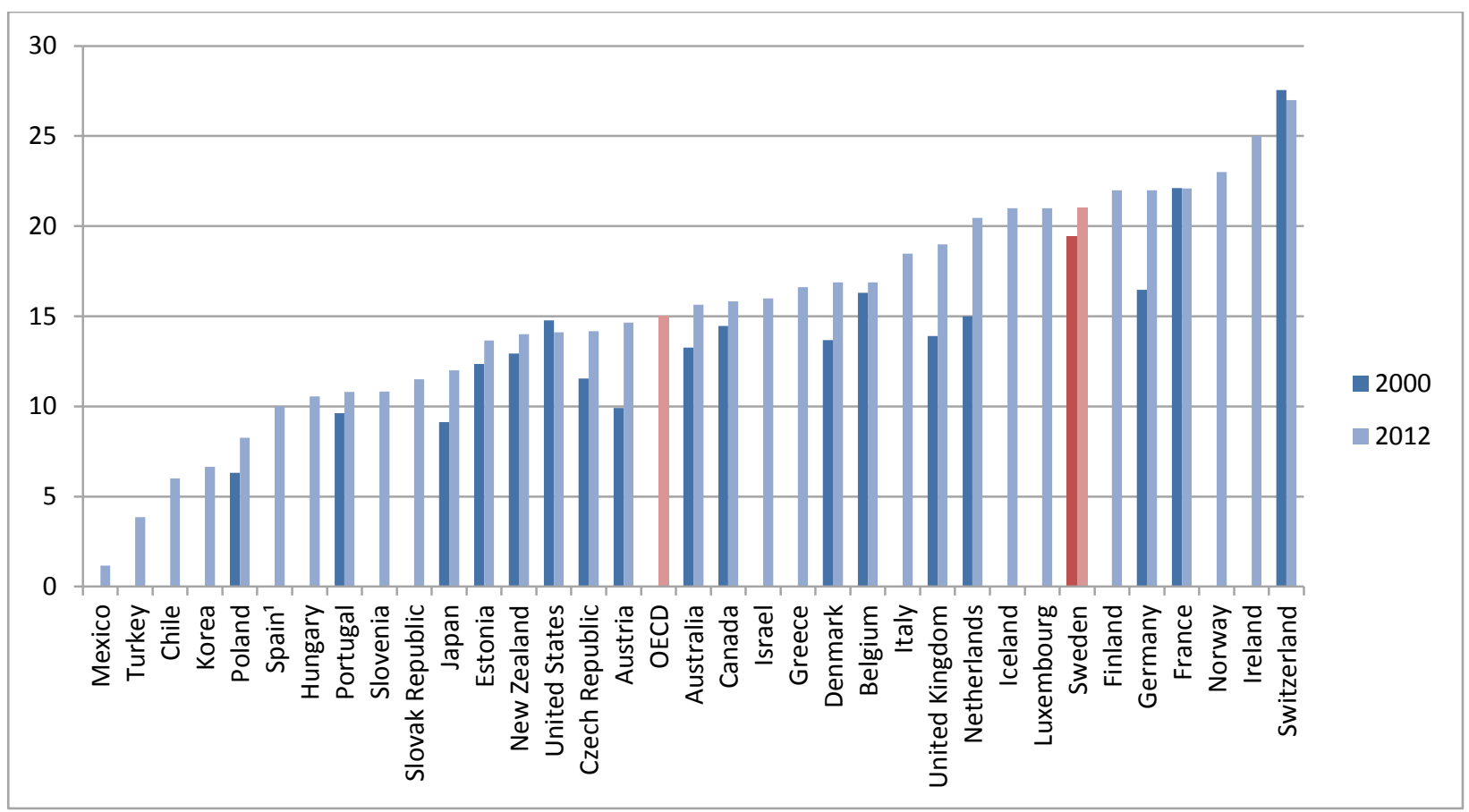

Source: OECD (2013a) Health Statistics 2013. http://dx.doi.org/10.1787/health-data-en.

97. A physician practicing as a psychiatric specialist is required to have undergone specialist training for at least 18 months in addition to having obtained a license to practice medicine. The normal length of time allotted for the completion of this standard medical training is 5.5 years. The specialist training takes place under supervision, during which time the doctor must also go through theoretical training (or specialist competence courses, known as SK courses). Psychiatrists, including those practicing child and adolescent psychiatry, adult psychiatry and forensic psychiatry, fall within the scope of the 2008 initiative by the National Board of Health and Welfare that outlined the guidelines and regulations concerning the knowledge, skills and attitudes required for the various medical specialties. The National Board of Health and Welfare is also in charge of medical accreditation (OECD Questionnaire, 2013).

98. The WHO indicates that, as of 2011, Sweden reports 28.3 (per 100000 population) nurses working in the mental health sector, which is high above the global average (5.8) and noticeably above the European average (21.93). However, it is nonetheless below other Nordic countries in this respect. Norway, for example, reported 120.88 mental health nurses per 100000 population. However, it must be noted that the WHO has reservations concerning such large gaps in reported numbers, speculating that "countries may have difficulty providing accurate figures for this category of professionals" given differences in definition (WHO, 2011).

99. It is of note that general medicine in Sweden is expected to incorporate specialised knowledge into their practice, and this wider scope of competence is also applied to nurses (who often perform duties that in some other EU countries lie exclusively within the scope of doctors) (OECD Questionnaire, 2013). For example, primary health care doctors are authorised to prescribe and continue the prescriptions of psychotherapeutic medication. Mental health nurses in Sweden, meanwhile, are expected to complete a general nursing degree, at which point they are permitted to work in a mental health area. There is the option to continue on to specialist training post-qualification in order to have more competence in working specifically with mental health issues, but this is not required (Oomen, 2007). However, primary health 
care nurses (unlike primary care doctors) in Sweden are not authorised by the Department of Health to prescribe or continue the prescription of psychotherapeutic medicines, nor are they authorised to independently diagnose and treat mental disorders within the primary care system (WHO, 2011).

100. At the same time, the number of nurses working in mental health has decreased since 2000, from 5748 total in 2000 to 5263 in 2009. The number of psychiatrists and psychologists, meanwhile, has risen over this same period. Psychiatrists, for example, have increased from 1386 to 1666 , while psychologists have grown in number from 4605 to 6129 . The number of occupational therapists have also risen significantly, from 6576 to 8250 (OECD Questionnaire, 2013). These trends could reflect the shifting demands for mental health professionals as care has moved increasingly towards community and outpatient care, as well as rising levels of mild to moderate mental disorders and reduced stigma which encourage the seeking of treatment.

101. Nonetheless, there is a reported shortage in terms of practicing psychiatrists as well as their professional recruitment, with an existing gap between those in need of psychiatric treatment (5\% to $10 \%$ of the population), and those actually receiving necessary care (3\% to 4\%) (Hadlaczky, 2012). Psychiatrist shortages vary across regions, with some regions being forced to employ psychiatrists as temporary doctors to fill in the gap of salaried psychiatrists. Not only is this method more expensive for the public, but it also lacks treatment continuity (as a patient can see different doctors on different visits), and can generally harm overall clinic quality due to discontinuity. Meanwhile, these difficult working conditions can in fact discourage interested individuals from seeking a career in psychiatry, which would in fact work to remedy the root cause of these difficulties. Sweden's most recent Mental Health Action Plan (2012-2016) aims to address these issues by increasing psychology training locations and creating psychiatry research posts (OECD, 2013).

102. Internet-based cognitive behavioural therapy (CBT) is one development used to a limited extent in Sweden in an attempt to provide services despite personnel shortages. CBT has been shown to be an effective tool in the treatment of panic disorder and depression, which, as mentioned, are on the rise in Sweden, and this approach allows patients to complete an online self-help programme while maintaining email contact with a therapist. Studies have shown that patients with panic disorder receiving this type of treatment do just as well as those receiving more traditional treatment. Depression, on the other hand proved to be effectively treated early on, as patients suffering from higher severity or more frequent depressive episodes responded less well. In general, however, this innovative approach shows promise of being part of a personnel gap filling solution (Bergström et al., 2010). CBT is currently supported by the Swedish Government's Rehabilitation Guarantee. The Rehabilitation Guarantee aims to reduce sickness absence by targeting mild to moderate mental ill health as well as back and neck pain (the two largest diagnostic groups in Sweden). The Swedish state has pledged an annual one billion SEK to the overall effort. In 2012, 35000 individuals received CBT under the Rehabilitation Guarantee (OECD, 2014b).

\section{1.ii. Primary care}

103. Primary care is most often delivered in primary care units. Organisation and delivery are managed regionally and locally and based on agreements and contracts between the regional government and the providers of local primary health care (OECD Mental health questionnaire, 2013). Of approximately 1100 primary care units, one-third are privately owned. The proportion of private units varies greatly between different county councils: for instance in Stockholm these private units account for approximately half of all the units while in the less densely populated northern county councils only a few of these units are private (Anell et al, 2012). Most commonly, these primary care units are composed of a team of health care professionals, including GPs, nurses, midwives, physiotherapists, psychologists etc. . 
104. Primary health care services are the first point of contact for people with mental health disorders. Residents in Sweden are free to choose their primary care provider, who may be either public or private (accredited by the county councils). People suffering from minor to moderate mental disorders, such as depression, anxiety or sleeping disorders, may be treated in primary care settings: indeed, primary care providers can initiate prescriptions for antidepressants and some other medications.

105. Figure 5 below illustrates the various types of providers consulted for mental health problems in OECD countries. In comparison to other OECD countries, the share of people consulting a GP is the smallest in Sweden, 53\%, compared to an OECD average of $73 \%$. This can be partly explained by the fact that general practitioners in Sweden do not act as gatekeepers to specialist services and that patients are able to consult directly with psychologists in primary care units (OECD, 2012b). Moreover, general medicine specialist training also includes tasks that require a deeper knowledge of common public health issues, mental health included (OECD Mental health questionnaire, 2013).

Figure 5. Type of provider(s) consulted for mental health problems, selected EU countries, 2010

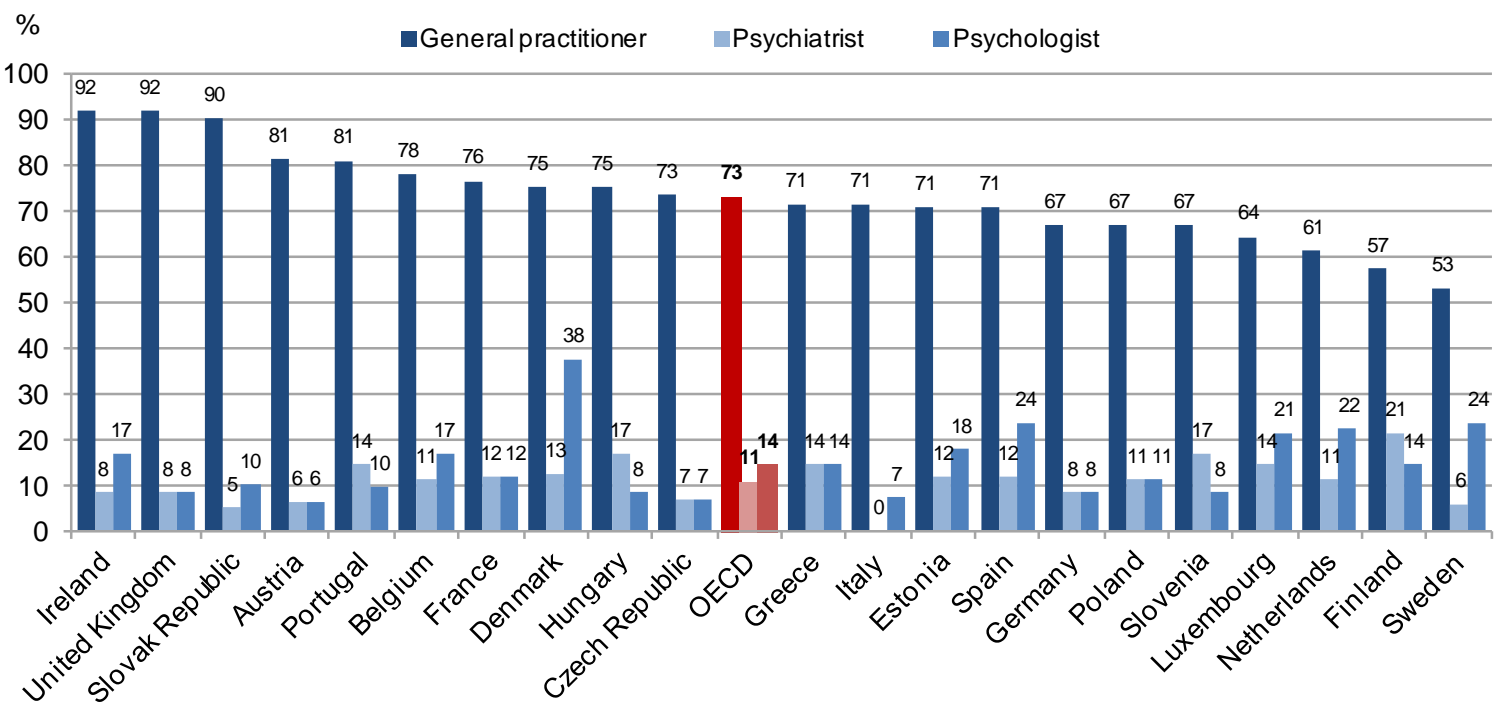

Source: OECD (2009), Health at a Glance, Paris, OECD Publishing.

\section{1.iii. Secondary and tertiary care}

106. As there is no gatekeeping in primary care to limit the access to specialist (mental) health services, many patients in need of treatment (for severe mental disorders in particular) may seek specialist level care directly. Psychiatric specialist services are mainly provided in psychiatric outpatient wards located in general hospitals.

107. Within the past ten years, the proportion of young men and women in psychiatric inpatient care has increased. Women are treated to a great extent for personality disorders, while men are mostly treated for mental disorders and behavioural problems due to psychoactive substances. Within the past 5 years, the utilisation of specialist psychiatric outpatient care has increased among young men, of which many are treated for hyperactivity disorders.

\section{Secondary outpatient care}

108. In 2010, the county councils reported approximately 780000 doctor's visits in specialist psychiatric outpatient care (National Board of Health and Welfare, 2012). These figures should, however, 
be interpreted with caution: a comparison with the aggregated statistics reported to the SALAR suggests that a large number of visits are missing from these statistics, mostly involving private health care providers (Anell et al., 2012). Variations between the county councils in terms of patients using outpatient services are also significant. A possible explanation to the variations between the county councils could be that access to a psychiatric specialist varies: Stockholm, for instance, has a higher number of specialists compared to many other county councils.

109. The use of outpatient services is highest amongst 18 to 24 year-olds (both women and men) and except for amongst children and adolescents (0-17), the proportion of women is higher than the proportion of men. Since 2005, the number of patients (women aged 18-24) using psychiatric outpatient services has increased by $18 \%$, from 390 in 2005 to 460 (per 100000 population) in 2010. These women, to a large extent, are treated for depressive and anxiety disorders. For men, there has been an increase amongst the youngest, in particular boys aged 0-17, where the number of patients has doubled within the same period, from 113 patients to 217 (per 100000 population). Among men aged 18-24 years, the number of patients increased by $32 \%$, from 260 to 345 patients per 100000 population. These young men are to a great extent treated for hyperactivity disorders and depressive episodes (National Board of Health and Welfare, 2012).

110. In terms of the frequency of visits in outpatient care, the average number of visits among 0 to 44year-olds is between 2 and 4 . There are also regional variations regarding the number of visits: for instance in Blekinge, Norrbotten and Östergötland, a larger proportion of the patients were reported as having only one visit, whereas in Stockholm and Örebro a relatively high proportion of patients had several visits, of which the majority were 25 to 44 year-olds.

111. In specialised outpatient care, $91 \%$ of patients had a primary diagnosis in 2010 . The highest proportion of women (28\%) and men (19\%) were treated for mood affective disorders. $16 \%$ of men were also treated for mental and behavioural disorders due to psychoactive substance use, and $13 \%$ were treated for neurotic, stress-related and somatoform disorders. $19 \%$ of women were also treated for the latter.

\section{Secondary inpatient care}

112. In 2010, a total of 94348 care episodes in psychiatric inpatient care were recorded in the patient register, comprising a total of 50055 patients (Public Health in Sweden, Annual Report 2013). Of these patients, women up to 24 years old accounted for the majority of patients. From 25 years on, on the other hand, the majority of patients were men.

113. Psychiatric inpatient care has increased amongst adolescents and young adults. In 2009 - 2011, 72497 women (516 per 100000 population) and 80479 men (572 per 100000 population) were treated in psychiatric inpatient care. Figure 6 illustrates the trends in psychiatric inpatient care for both men and women between 1991-2011, a period during which the number of psychiatric beds declined sharply. During the period, admissions to inpatient care for both men and women in all age groups have also decreased, with the exception of 15-24 year-olds (National Board of Health and Welfare, 2013). This increase can be largely explained by the sharp increase of depression and anxiety disorders amongst adolescents in recent years (National Board of Health and Welfare, 2009 -Public Health report). 
Figure 6. Psychiatric inpatient care for men and women between 1991-2011

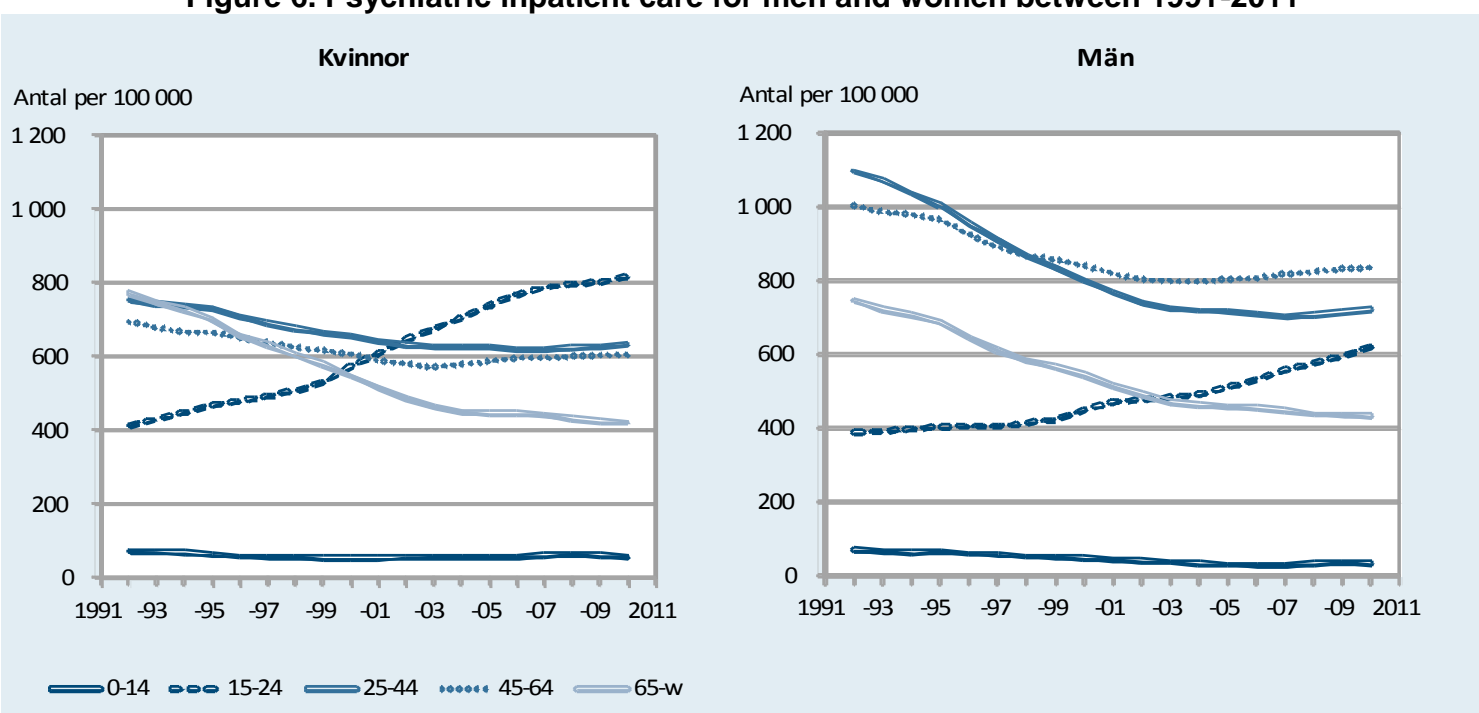

Source: National Board of Health and Welfare (Socialstyrelsen) (2013), "Folkhälsan i Sverige Årsrapport 2013" (Public Health in Sweden, Annual Report 2013), Stockholm, National Board of Health and Welfare.

114. Primary and secondary diagnoses (where relevant) are also reported, according to the Swedish version of the WHO classification system (ICD-10), to the patient register. Of all the contacts in psychiatric inpatient care in 2010, 97.2\% had a primary diagnosis (Public Health in Sweden, Annual Report 2013). Primary diagnoses in psychiatric inpatient care in 2010 are illustrated in Figure 7 below. The majority of patients (35\%) were treated for some type of substance abuse (mostly alcohol-related), followed by mood affective disorders (20\%), schizophrenia (14\%) and neurotic stress-related and somatoform disorders $(12 \%)$.

Figure 7. Primary diagnosis according to ICD-10 codes for treatment period that terminated in 2010

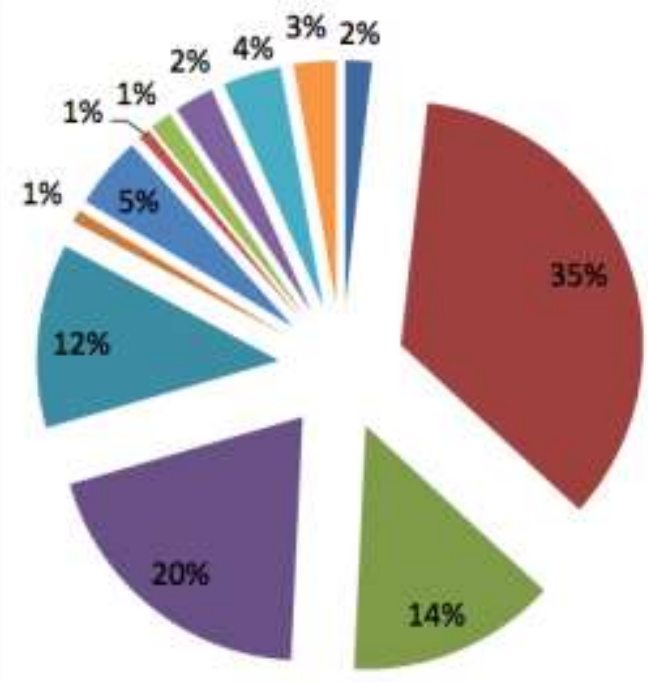

= Organic, including symptomatic, mental disorders (FOOF09)

Mental and behavioural disorders due to psychoactive substance use (F10-F19)

in Schizophrenia, schizotypal and delusional disorders (F20-F29)

"Mood (affective) disorders (F30-F39)

Neurotic, stress-related and somatoform disorders (F40-F48)

m Behavioural syndromes associated with physiological disturbances and physical factors (F50-F59)

in Disorders of adult personality and behaviour (F60-F69)

inevelopmental/Learning disabilities (F70-F79)

Disorders of psychological development (F80-F89)

- Behavioural and emotional disorders with onset usually occurring in childhood and adolescence (F90-F98)

Source: National Board of Health and Welfare (Socialstyrelsen) (2013), "Folkhälsan i Sverige Ärsrapport 2013" (Public Health in Sweden, Annual Report 2013), Stockholm, National Board of Health and Welfare. 
115. The number of psychiatric beds in Sweden is relatively low compared to other OECD and Nordic countries as illustrated in Figure 8. Moreover, the proportion of these beds has considerably decreased since 1995: the number of psychiatric beds has halved since 1995, from 95 in 1995 to 46 in 2012 (per 100000 population). This low number can largely be explained by Sweden's long process of deinstitutionalisation and its investment in the development of outpatient services (the construction of psychiatric outpatient units in general hospitals and dismantling of separate mental institutions). The psychiatric care reform (1995) also focused on developing community/intermediate services for long-term patients, and as a result the number of beds went down while the number of housing services increased (see section 1.1) (OECD, 2013).

Figure 8. Psychiatric beds per 100000 population in selected OECD countries, 1995 and 2012

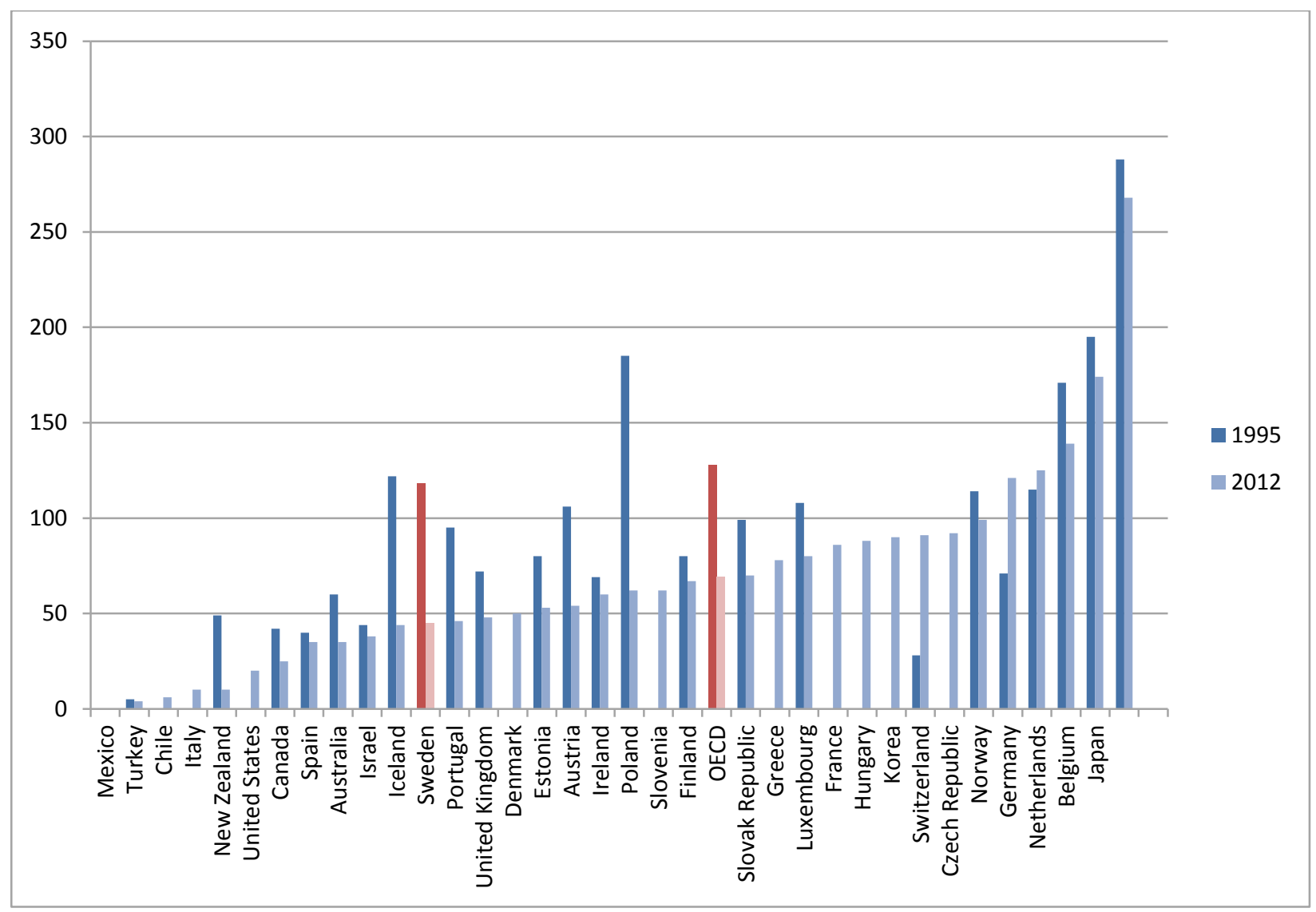

Source: OECD (2013), OECD Health Statistics 2013, OECD Publishing, Paris, www.oecd.org/health/healthdata

116. The average length of stay (ALOS) for mental and behavioural disorders (dementia included) in Sweden is also below the OECD average, but nonetheless higher than in two other Nordic countries (Denmark and Norway), which exhibit the lowest ALOS. Since 1998 (three years after the Psychiatric Care Reform) the average length of stay has significantly decreased, from 22.8 to 15.6 days in 2011 (-31.5\%) (OECD, 2013). 
Figure 9. Average Length of Stay, 2000 and 2011 (or nearest year available)

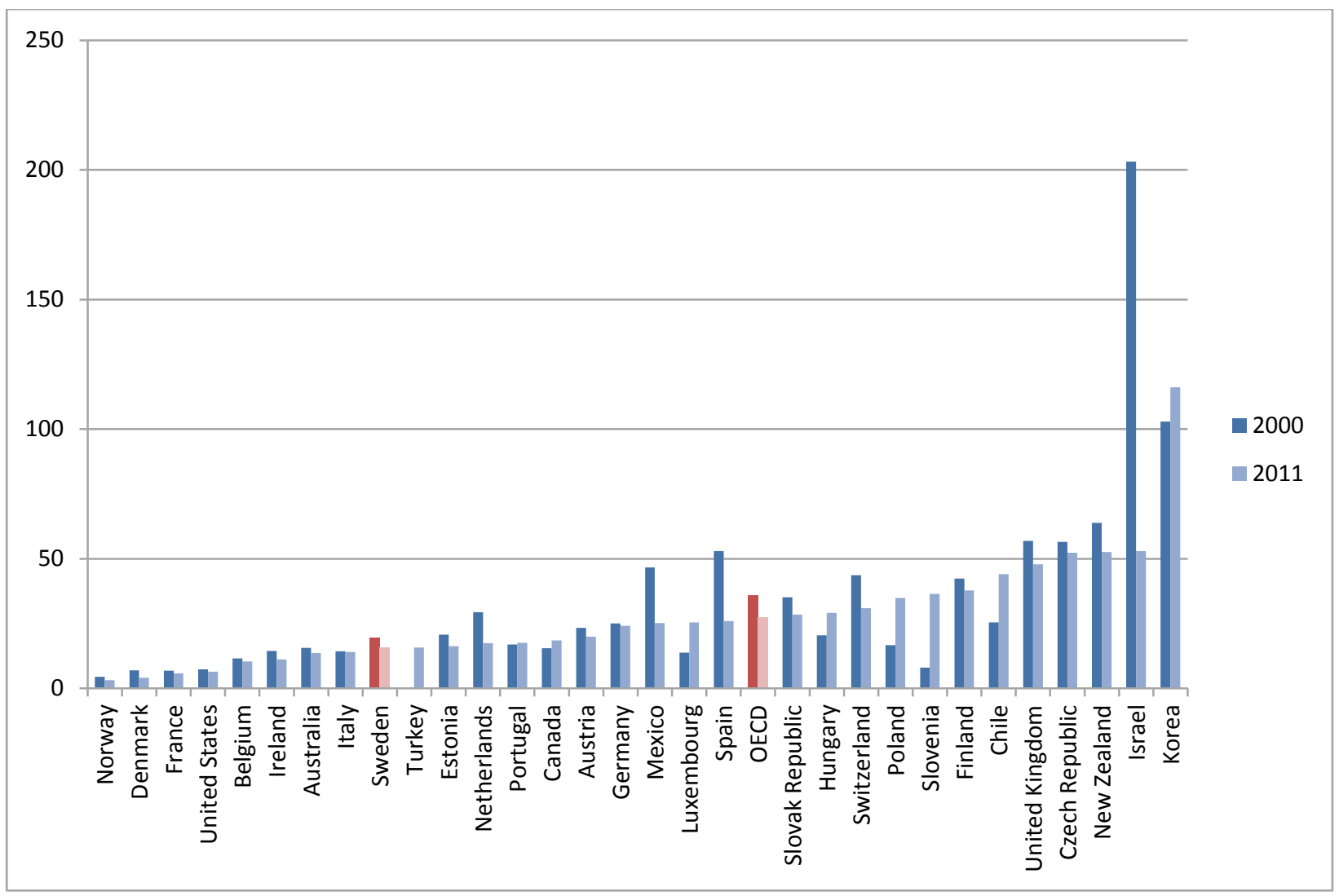

Source: OECD (2013), OECD Health Statistics 2013, OECD Publishing, Paris, www.oecd.org/health/healthdata

\section{Housing services}

117. The provision of housing and employment for people suffering from mental disabilities falls under the responsibility of municipal social services. In practical terms, this requires the Social Welfare Committee to remain apprised of the living conditions of affected individuals within its municipality and to provide outreach so that they are aware of what rights they have (OECD Questionnaire 2013).

118. The issue of housing for individuals with mental disabilities has been of increasing importance since the deinstitutionalisation process began in earnest in the 1960s, as asylums were not only a means of treatment, but of housing. In 1990, it was reported that approximately $20 \%$ of inpatients were kept in hospital due primarily to a lack of housing alternatives (Melke, 2010). In 1995, the Municipal Financial Responsibility Act came into effect, and the municipalities assumed the financial responsibility for such individuals who had to stay in hospital to avoid homelessness. State grants further encouraged the development of group homes during the 1990s.

119. The municipalities' responsibilities are outlined in the Social Services Act since 1982, and the Disability Act since 1994. In the former, the obligation of housing support applies both to the general population as well as to specific groups (including those suffering from mental problems). The latter piece of legislation outlines municipal obligation vis-à-vis defined disability groups. Those affected by mental illness must be able to prove that the need stems from a mental impairment that is not the result of ageing, is enduring, important, and causes significant daily difficulties. They must also be able to prove that their needs are not being met in present conditions. 
120. Qualifying individuals may receive aid for independent living, which assists them in getting housing of their own. This can be a standard flat from either the private or public sectors, or a special flat designed for certain groups. Another option is to acquire a "social contract" that allows the social services to act as a guarantor when dealing with a private landlord. For those requiring more comprehensive care, there are sheltered housing options that provide staff on either a full- or part-time basis. If the individual has an income, municipalities can charge for the housing service (rent and other care) on a sliding scale (Melke, 2010).

121. Within this system, a 2003 study carried out by the National Board of Health and Welfare reported that approximately 8000 such accommodations were accounted for in Sweden, distributed across 850 entities. Two-thirds were classified as "home-like", while the remaining one-third was found to be "institution-like". Housing was listed as "permanent" for $86 \%$ of residents. Although Sweden as a whole was found to have an overall surplus of available beds, some municipalities were forced to direct a certain number of affected individuals to other municipalities due to housing shortages. This was found to take place at a rate of $20 \%$, although it was especially high in Stockholm, where it was $43 \%$. The findings suggest a shortage of housing in the largest municipalities, which is to be expected given the coexisting over-representation of mental disorders in those areas (Melke, 2010). However, it does draw attention to the need for housing development targeted to regional needs.

\subsection{Child (and adolescent) mental health}

122. Within the past few years, there has been a rising concern about the increase of mental health disorders among children and adolescents. National and regional strategies have drawn attention to and focused on stopping this rising trend. The mental illness action plan for 2012 - 2016, for example, specifically targets mental health issues among children and youth as a priority in its agenda (discussed in Section 3.3). Government welfare bills have listed children and adolescents' mental and physical wellbeing as a top priority. Beginning 1 January 2013, the Social Services Act in Sweden contains new measures that strengthen support and protection for children and youth who are at risk of being neglected or abused. These measures include a stricter duty of notification in case of suspected neglect or abuse, the requirement of a child-specific social worker, clearer social welfare committee responsibilities, training and support to family homes, and a closer adaptation to the Convention on the Rights of the Child.

123. In addition, a National Strategy for developed parental support was put forth in March 2009. This initiative aims to provide parental support throughout a child's development (age 0-17), promote health and positive development throughout these formative years and protect the child from illness and social problems as much as possible (OECD Questionnaire 2013). These measures are intended to improve overall mental and physical wellbeing of children and youth in Sweden.

124. As much as possible, policy aims to keep children with special needs within mainstream schools and to help them within these settings. The Ministry of Education is charged with the shaping of the education system through the development of curricula, national objectives and guidelines. Within this framework, municipalities and independent providers implement educational activities, organise school services, allocate resources and ensure that educational goals are met. Individual districts and schools are then entrusted with a large degree of autonomy to organise local schooling. This system is shaped around mandatory primary school ("Grundskola") for children 7 to 16 years old, which is then followed by an elective three year secondary school program ("Gymnasieskola"), during which students can either prepare for higher education or receive vocational schooling.

125. Special schools exist to accommodate children with dealing with more severe functional problems and disabilities. These schools are either special schools ("specialskolor") or schools specifically for pupils with intellectual disabilities ("särskolor"). 
126. Sweden's approximately 2 million children (0 to 18 years old) represented $22 \%$ of the overall population in 2009. Of this group, approximately 5\% (or 100000 children) are treated for some kind of psychiatric issue each year, while about $15 \%$ are in contact with psychiatric services at some point during childhood or adolescence. It has been estimated that psychiatric services for children and young people cost approximately SEK 2 billion annually (SALAR, 2009).

127. Most boys and girls who used child- or adolescent psychiatric services were treated for hyperactivity disorders (F90), which also occur to a large extent among men aged 18 to 24 years. Among young women (18-24), a large proportion of those in contact with psychiatric services have been treated for anxiety disorder.

\subsection{Forensic mental health}

128. A separate legislation, the Forensic Psychiatry Act (1991), outlines the provisions for and regulates the Swedish forensic system (see section 1.2). This legislation is designed to treat individuals who have committed serious crimes and are judged to have a serious mental disturbance. As such, this Act is mostly used within the context of the penal system and applies to people sentenced to mandatory mental care. For example, it lays out the terms for leave and compulsory measures, and provides a framework in order to judge when sufficient conditions have been met to justify terminating treatment.

129. A particular characteristic of the Swedish system is that all offenders are considered responsible for the crimes they have committed. Thus, it is impossible to plead not guilty by reason of insanity; if someone is found to have committed a crime while suffering from a mental affliction, that person is sentenced to forensic psychiatric treatment. However, a person under the influence of a severe mental disorder cannot be sentenced to prison. The individual is instead taken into custody under the Compulsory Mental Care Act.

130. 1476 Swedish forensic patients were assessed in the Swedish National Forensic Psychiatric Register (SNFPR) for Swedish forensic patients for the year 2010; 1251 (85\%) were males and 225 (15\%) were females (Innocenti et al., 2014). Sweden has thirty-one clinics used for forensic psychiatric purposes, and these clinics treat $94 \%$ of such patients. The remaining forensic psychiatric patients are treated at general psychiatric clinics.

131. The primary goal of forensic psychiatric care is to prevent recidivism, and correspondingly, to reduce the recurrence of mental illness and substance abuse. The period of care for affected individual's spans, on average, approximately five years. In Sweden, the national rate of recidivism amongst forensic psychiatry patients was just below 21\% (recidivism including incidents reported to the police or constituting grounds for report, violence against caregivers or others as well as various other forms of criminality). The correlating study, however, was limited In that the data used was based on self-reporting, as access to criminal records were not retrievable due to Swedish legislation limiting such availability (National Board of Health and Welfare, 2010b).

132. A 2011 study carried out using subjects court-referred to the Department of Forensic Psychiatry in Gothenburg, Sweden found evidence that forensic psychiatric treatment is an effective approach when dealing with criminal offenders who are also affected by mental illness. Of the individuals treated with psychiatric care, there were five reconvictions (representing $11 \%$ of the study population), compared to 15 amongst those sentenced to prison (28\%). The authors conclude that "judging from these results, and keeping in mind that offenders are not randomized to these sanctions but sorted by a detailed legal framework, risk management and prevention of criminal recidivism seems to work better in the forensic psychiatric care system than in the prison-parole system" (Nilsson, 2011). These positive results could be due to several factors, including the individualised nature of psychiatric treatment, or the more 
comprehensive support system associated with Swedish forensic psychiatry programs, including transitional accommodations.

\subsection{Minorities and excluded groups}

133. The primary minority groups in Sweden are Sami (recognised as indigenous), Jews, Tornedalers, Roma and Swedish Finns. In June 2008, the Swedish government commissioned the Swedish National Institute of Public Health (SNIPH) to carry out an assessment of the health situation of national minority groups, the results of which were released in 2010. The purpose was to be able to compare the overall health situation of minorities to the majority population in order to facilitate the development of adequate public health strategies to address inequalities. Four of the five groups - Swedish Finns, Roma, Tornedalen women and certain concentrated portions of the Sami population - show evidence of elevated mental health issues. Among the Sami, a high rate of suicidal thoughts among reindeer herders is reported. All of these minorities reported low trust in national institutions, which limit their tendency to seek health care.

134. Recommendations were made to the government to address this health gap. These include the establishment of regional competency centres to improve health among minority populations, education of cultural advisors among national minorities, education of health care professionals and civil servants to enable them to better serve these groups, investigation of adequate methods to assess and follow up on the health situation of national minorities, the mainstreaming of child, youth and elderly perspectives in concerned institutions, and the establishment of a commission to investigate how to address national minority issues at an intersectional level.

135. Of course, there are more ethnic minorities in Sweden than are listed as "national minorities." Sweden's demographic landscape has been changed not only by normal immigration/emigration rates, but also by the settlement of refugees arriving from the Middle East, Africa, Asia, Latin America, Eastern Europe and the Balkans in recent decades. In 2012, Statistics Sweden reported that 7\% of Sweden's population was composed of foreign citizens, and $15.4 \%$ was foreign-born ${ }^{2}$.

136. In 2001, the National Board of Health and Welfare found that the Swedish health care system provides health care to ethnic minorities and the majority population on a relatively equal footing. However, a difference was observed between the two groups in the frequency of psychiatric medication. Ethnic minorities were prescribed analgesics and antidepressants at a higher rate than Swedish-born patients, and hypnotic and sedative drugs at a much higher rate. Although the study was able to explain the increased use of analgesics and antidepressants as being due to a correlating higher prevalence amongst these groups of conditions requiring such medication, this is not the case for hypnotic and sedative drugs. This gap rather points to differences in the way Swedish-born and ethnic minority individuals receive mental health treatment in Sweden. For example, it has been shown that primary care practitioners are more likely to prescribe benzodiazepines than psychiatrists, and minorities are more likely to be treated for psychiatric conditions in primary (as opposed to psychiatric) care. Communication barriers could also help explain this difference, which can make behavioural or psychotherapeutic therapies prohibitively difficult (Hjern 2001).

137. The Swedish government adopted a new minority policy in 2009 at the same time as its ratification of the Council of Europe minority conventions. This was implemented as part of an effort designed to equip national minorities with what they need "to assimilate, develop, preserve and reclaim their languages" (Government Offices of Sweden, 2010). In terms of health care, this Act on National Minorities and National Minority Languages aims to provide support to the Health and Medical Service Act in its efforts to provide equal health care to Sweden's entire population regardless of age, gender, the

2 http://www.scb.se/Pages/TableAndChart___26041.aspx 
ability to take initiative, education, capacity to pay, nationality or cultural differences (including language). Given existing language barriers and the importance of effective communication in effectual psychiatric treatment, such an effort is of special concern to the professional mental health community.

\section{Mental Health Care Financing and Expenditure}

\subsection{Financing of mental health services}

138. Given that mental health services are an integral part of health services, the county councils are responsible, as for other services, for the financing of mental health care. The Swedish health system is mainly financed through general taxation by the 21 county councils. Approximately 80 percent of the total health care budget is financed through regional taxation. 15-20 percent comes from state grants and patient fees only cover a very small part. The county councils are responsible for purchasing all health care for their inhabitants through district regional health authorities. Most commonly, GPs and other health professionals are salaried or contracted. County councils also own the majority of hospitals.

\subsection{Provider-payment mechanisms}

139. Mental health care professionals work primarily on a salaried basis in order to facilitate Sweden's universal health care plan. Although all Swedish citizens are entitled to subsidised mental health care, flatrate charges are set by the counties, and variation can be significant depending on the region. Nonetheless, outpatient care covered by this system has a relatively low individual payment cap (nationally applied) on what people can be required to pay out of pocket (about EUR 100 per year). Inpatient care operates slightly differently, and this payment ceiling does not apply in such cases, although there is a national cap on daily charges (about EUR 9 per day). Private care - operating completely separately from the public sector - has no regulations or limitations on what can be charged (Melke, 2010).

140. However, a shortage of salaried psychiatrists has led to a situation in which county councils must turn to hiring private doctors on a temporary basis, which is a much more expensive option. The growing concern is that this is not only financially unsustainable, but also harms overall quality of care, as rotating doctors leads to a lack of treatment continuity, and creates more difficult working conditions, which in turn discourages individuals from seeking a career in psychiatry (see section 4.1.i) (OECD, 2013).

141. County councils are in charge of how hospitals within their domain are reimbursed. Most county councils have been using a purchaser-provider model since the 1990s, in which payment is established according to volume of activities. This entails purchasing organisations working with hospital health care providers in order to draw up contracts covering finances and activities, generally based on fixed per-case payments with price or volume ceilings and quality components. However, given the high level of autonomy granted to county councils, payment mechanism details vary widely across Sweden's administrative regions (Street et al., 2007).

\subsection{Mental health care expenditure}

142. Total health spending accounted for 9.1\% of GDP in Sweden in 2012. Compared to other Nordic countries, health expenditure was the second highest after Denmark. Of total net expenditure on health and medical care services in Swedish county councils and regions in 2010 (202 billion SEK), specialist psychiatric care accounted for 8\%, pharmaceuticals excluded (SALAR, 2011a).

143. Private health care insurance is limited and primarily provided and paid by employers (Anell et al 2012). In terms of total health expenditure, the share of private insurance is marginal, accounting for merely $0.1 \%$ in 2000 , which increased only to $0.3 \%$ in 2010 (OECD, 2012b). It typically provides supplementary coverage (mainly coverage for elective surgery) to the public health system. The demand 
for voluntary health insurance has however grown: private insurance guarantees a rapid access to ambulatory care when needed. In 2010, 382000 people had supplementary voluntary insurance, compared to approximately 103000 people in 2000 (Anell et al., 2012).

\section{Expenditure on specialised psychiatric services}

144. Expenditure on specialist psychiatric care includes inpatient care and outpatient care and specialist measures for mental disorders or mental disabilities. The scope of specialist care comprises general psychiatry, child and adolescent psychiatry, forensic psychiatry as well as services for substance or other types of abuse (eating disorders, gambling, computer abuse etc.) (SALAR, 2011a).

145. Hospital expenditure in Sweden accounted for 125 billion SEK (NCU - 1 EUR: approximately 8.4 SEK) in 2010. Around $93 \%$ of specialist-level care was provided by the county councils, whereas the remaining $7 \%$ of services were purchased from private providers. Somatic care accounted for approximately $85 \%$ of the expenditure, while the remainder (15\%) was spent on psychiatric care (SALAR, 2011b).

146. It is worth noting that Stockholm reports significantly higher spending in specialised psychiatric care than other regions. This could be due to the demonstrated rise in mental ill-health rates observed in metropolitan areas. Age could also be a contributing factor, as mental illness among Swedish youth has been seen to be on the increase. Younger people tend to be more likely to require psychiatric care (see section 2) and Stockholm has a relatively young population. This age element, however, is not necessarily applicable. Uppsala, for example, also has a young population, but reports psychiatric care costs that are nonetheless in line with the national average (National Board of Health and Welfare, 2010).

147. Production costs of hospitals amount to just under 98 billion SEK. Expenditure on the 7 regional hospitals accounted for 42 billion SEK, on 21 county hospitals for 42 billion SEK and on 28 smaller hospitals for 13.5 billion SEK. As regards to the expenditure on outpatient and inpatient care on smaller county hospitals, $7.7 \%$ was spent on general psychiatry (including forensic psychiatry), and $0.9 \%$ on child psychiatry. For county hospitals, the corresponding figures were $13 \%$ and $2.5 \%$. Finally, $5.2 \%$ was spent on general psychiatry and $0.9 \%$ (the least of all medical specialties) on child psychiatry in regional hospitals. This implies that the county hospitals bear the largest share of specialist psychiatric out- and inpatient services (SALAR, 2011b).

\section{Discussion, innovative practices, and conclusion}

\subsection{Outcomes and quality indicators}

148. Sweden has been a proactive actor in the advancement of national mental health, developing locally targeted policy and programmes, as well as cooperating with international mental health efforts. National indicators can be followed over time by looking at the Statistics Sweden database (Statistics Sweden, 2014). This database provides a number of quality indicators related to (mostly mild or moderate) mental health issues, including problems of anxiety, worry or fear, sleeping disorders, and numbers of professionals working in the field. Nonetheless, this database could benefit from a greater number of mental health-targeted statistics.

149. Sweden has also cooperated with other states in order to enable the exchange of information with the goal of a general elevation in the quality of care. In 2007, for instance, Sweden was involved in the launch of the third Nordic Council's health indicator project, which served to amass a comprehensive set of mental health quality indicators across the Nordic countries. In 2011, a report was prepared to allow for the comparison of Nordic countries, specifically including information on indicators that could be used as a basis for the monitoring of mental health services. A number of areas were incorporated, including 
measurement of generic indicators mental health services, compulsive measures, electroconvulsive therapy, levels of schizophrenia, hospitalisation for depression, bipolar disorder, attention deficit hyperactivity disorder, and patient/family member-rated quality of services (Nordic Council of Ministers, 2011).

150. The Swedish National Board of Health and Welfare has also developed a multi-dimensional quality framework, "Good Care", to monitor health care performance. The framework covers several dimensions of care including effectiveness, safety, patient-centeredness, timeliness, equity and efficiency. The framework utilised more than 30 process and outcome indicators to compare quality of psychiatric care across regions or patient groups. In summary, while large regional disparities in the quality of mental health care did not appear to exist, there were large disparities in somatic care outcome between patients with and without a co-morbid mental disorder.

151. In terms of national outcomes resulting from mental health policy and programming, Sweden has seen quantifiable improvements in target areas. For example, Sweden was amongst the first countries to develop an anti-suicide initiative. Although suicide appears to be a growing problem amongst Swedish youth (15 to 24 years old), this growth is not dramatic and overall suicide rates declined, on average, by 15\% between 1995 and 2009. Nonetheless, suicide rates remain higher than could be hoped, with Sweden's numbers behind only Finland amongst the Nordic countries. Ratified in 2008, the National Programme for Suicide Prevention aims to accelerate progress in this domain.

152. Efforts to tackle the stigma surrounding mental health have also proven to be effective. Stigma can have a serious impact on people struggling with psychological issues, as such a negative view can have an undesirable shaming effect that discourages individuals in need from seeking treatment. Furthermore, negative views of mental illness can lead to reduced hiring of such individuals and even hesitancy to have them in close proximity (such as in one's immediate neighbourhood). These conditions can in fact serve to exacerbate mental health problems and inhibit recovery. Encouraging signs can be seen, however, in the Hjärnkoll anti-stigma initiative, as a study found that improvements have been measured between 2009 and 2011 (for example, opinions have improved vis-à-vis the public view of having a person with a mental illness as a neighbour, and one for every two people initially expressing disfavour have changed their opinion).

\subsection{Discussion and key messages}

153. Sweden has demonstrated a commitment to deinstitutionalisation and ongoing transition to improved community care. The number of psychiatric beds (per 100000 population) has been cut in half during the past two decades, decreasing from 0.95 in 1995 to 0.48 in 2010. Increased funding for outpatient services can assist in explaining this decline. Moreover, the average length of stay in hospital for mental and behavioural disorders (including dementia) has declined from 22.8 days in 1998 to 15.6 days in 2010, representing a reduction of $31.5 \%$. While this latest rate is below the OECD average, it is significantly higher than two other Nordic countries (Denmark and Norway). Comprehensive housing services exist in Sweden for those in need of them, and improvements in this domain can serve to explain, in part, the reduction in average lengths of stay in hospital. There appears to be an overall adequate supply of specially provided lodging across the country (evidenced by empty beds), but certain regions (particularly metropolitan areas) have difficulties with housing shortages that should be addressed.

154. Despite generalised improvement across the Swedish population, certain groups have nonetheless been singled out in recent years as needing more concentrated attention vis-à-vis mental wellbeing. Swedish workers and youth are two so identified groups. Mental disorders represent the most common work-related health problem in Sweden, and occupational health services should be further developed. However, it has been observed that the general trend of mental ill health amongst Swedish workers of all 
ages has been seen to reverse since 2001 and be improving. On the other hand, this is not the case when workers up to 29 years old are singled out. Among this latter group, disability claims have been filed and approved in increasing numbers. Sweden may thus want to consider the development of a disability benefit scheme for individuals under 30 years old that emphasizes vocational rehabilitation and replaces disability benefit entitlement for youth for prolonged schooling with a study grant. To inhibit early dependence on disability benefits, labour policies should be put in place to foster labour demand and hiring of youth.

155. Mental ill health amongst children and adolescents in general has been on the rise in recent years, reflecting a need for increased preventive care within this population. Mental disorder amongst women in particular within this group is especially on the rise, with outpatient services increasing by $18 \%$ from 2005 to 2010 (from 390 per 100000 population to 460). Amongst this same age group, meanwhile, the number of male outpatients has increased by $32 \%$, although from a lower starting point (from 260 to 345 per 100 000 population). Boys aged 0-17 have also seen a notable increase, with the number using outpatient services nearly doubling between 2005 and 2010, from 113 to 217 (per 100000 population). The majority of these cases are treated for mild or moderate conditions, especially depression and anxiety. Overall, the percentage of men and women 20 to 24 years old hospitalised for depression more than doubled from 1990 to 2010 .

156. These fairly dramatic increases could be due to several factors. The changing job market is likely an underlying cause, as there are significantly fewer employment opportunities for compulsory and uppersecondary graduates than there were twenty years ago. Furthermore, those that do find work often face poorer working conditions (Danielsson et al., 2012). Another factor could be a reduction in stigma associated with mental illness, which would correlate to greater willingness to acknowledge a mental disorder and seek treatment. In any case, continued targeting of mental health care and outreach to this group will be necessary in order to minimise longer-term health problems. The national strategy for developed parental support is a positive initiative that aims to provide families with the support necessary to nurture mental health in children from a young age.

157. Swedish minorities are also in need of additional attention in order to ensure that their mental health needs are met. Sweden's public health policy, under the Medical Services Act, aims to provide health care on an equal footing to all, regardless of age, gender, the ability to take initiative, education, capacity to pay, nationality or cultural differences. Overall, minority groups are well-served in Sweden both officially listed national minorities as well as other minority groups present in the country. However, there is nonetheless evidence of generally reduced mental health levels amongst Swedish minority groups, which indicates the need for culturally adapted outreach efforts. There is also evidence that such groups are more frequently prescribed hypnotic and sedative drugs than the majority population, which points to a general difference in the way their treatment is approached. Language barriers may play a large part in explaining this treatment gap. Sweden is already taking steps in an attempt to address this issue, placing health care support within the mandate of the Act on National Minorities and National Minority Languages (2010).

\subsection{Ongoing mental health agenda; next wave of agenda}

158. As of May 2012, Sweden has committed to an extended action plan for mental illness that is scheduled to run through 2016 (see section 3.3). Having already undergone a significant reform of its mental health system in 1995 (Psychiatric Care Reform), this most recent item on the policy agenda is oriented less towards structural reform, and more towards addressing the needs of perceived vulnerable groups requiring more targeted mental health care.

159. This programme will build upon previous projects, which grew out of a perceived need to address weaknesses in the mental health system (these problems had been pushed into the spotlight by a series of 
high-profile homicides committed by people with mental disorders). As part of the 2007-2011 initiative, Sweden has been working to improve county capacity to provide appropriate housing and daily activities, as well as better national planning and coordination, national psychiatric care (general and forensic) standards setting, and a more developed national monitoring system.

160. Currently in progress, the 2012-2016 action plan has been guaranteed SEK 870 million per year in order to pursue its mandate. Working in conjunction with SALAR, the initiative aims to use economic incentives to local authorities to improve mental health services. Specifically, the plan identifies two groups as in need of enhanced care and outreach: children and youth, and people suffering from significant psychiatric problems. Increasing the rate of employment for individuals with mental health issues is also a listed priority. A final progress report will be presented in 2017 by the Swedish Agency for Health and Care Services Analysis, which will be following the action plan and evaluating its impact.

161. Moreover, Sweden has placed suicide prevention on the official agenda, ratifying the National Programme for Suicide Prevention in 2008 (see section 3.4.1). It is organised around a nine-point strategy that aims to reduce opportunity for suicide, increase education and competence, and improve analysis monitoring. Part of the program, labelled the "Lex Maria", aims to report all suicides occurring within the healthcare system or within 28 days of leaving it. This is meant to allow authorities to pinpoint where treatment can be improved and better tailor treatment to suicidal patients. Given that approximately $20 \%$ of all suicides in Sweden are committed by psychiatric inpatients, this initiative establishes a system via which it will be possible to better quantify and address risk factors. As mentioned above, the average rate of suicide in Sweden is in decline (NASP, 2012).

\subsection{Outstanding and innovative initiatives: best practice examples}

- Locally targeted care via responsibility delegation (national/regional/local)

- National strategy for developed parental support targeting early mental wellness

- Internet-based cognitive behavioural therapy

- "Lex Maria" suicide reporting initiative 


\section{BIBLIOGRAPHY}

Anell , A., Glenngård AH, Merkur S. (2012). Sweden: Health system review. Health Systems in Transition, , 14(5):1-159.

Belfrage, H., Fransson, G. (2000), "Swedish forensic psychiatry: a field in transition", International Journal of Law and Psychology, Vol. 23, Iss. 5-6, pp. 509-514.

Bergström, J. et al. (2010), “Internet- Versus Group-Administered Cognitive Behaviour Therapy for Panic Disorder in a Psychiatric Setting: A Randomised Trial”, BMC Psychiatry, Vol. 10:54.

Bolling, J., Rosenberg, D., Kawesa, V. (2009) "Mental health study - Sweden” European Union Agency for Fundamental Rights (FRA)

Danielsson, Maria et al. (2012), "Health in Sweden: The national public health report", Scandinavian Journal of Public Health, Vol. 40, Supp. 9.

European Commission (2008)Report of the Ad Hoc Expert Group on the Transition from Institutional to Community-based Care European Commission

Government Offices of Sweden (Regeringskansliet) (2010), "Sweden's report to the Council of Europe on the European Charter for Regional or Minority Languages", Government Offices of Sweden, Stockholm.

Hadlaczky, G., A. Stefenson, D. Wasserman (2012), “The state of psychiatry in Sweden”, International Review of Psychiatry, Vol. 24(4), pp. 356-62.

Hansson, L \& Markstrom (2014). "The effectiveness of an anti-stigma intervention in a basic police officer training programme: a controlled study”. BMC Psychiatry. 14: 55.

Hjern, Anders (2001), "High use of sedatives and hypnotics in ethnic minorities in Sweden", Ethnicity \& Health, Vol. 6, Iss. 10, pp. 5-11.

Hyvönen, J. (2008) "Suomen psykiatrinen hoitojärjestelmä 1990-luvulla historian jatkumon näkökulmasta" (The Finnish Psychiatric Health Services in the 1990's from the Point of View of Historical Continuity) University of Kuopio

Innocenti, A., Hassing” L., Lindqvist A.S., Andersson, H., Eriksson' L., Hagelbonn, of Ku, F., MF.,lb, N., Nilsson, T., Hofvander, B., Anckarser, 'H. (2014). "First report from the Swedish National Forensic Psychiatric Register (SNFPR)”, International Journal of Law and Psychiatry..Volume 37, Issue 3

Lindelius, B., E. Björkenstam (2012), "Involuntary treatment in Swedish psychiatry", European Psychiatry, Vol. 27, Sup. 1, p. 1. 
Melke, Anna (2010). "Mental health policy and the welfare state: a study on how Sweden, France and England have addressed a target group at the margins", dissertation presented to the School of Public Administration, University of Gothenburg, Gothenburg.

NASP (2012), "Suicide in Sweden" National Centre for Suicide Research and Prevention of Mental IllHealth, Stockholm, http://ki.se/ki/jsp/polopoly.jsp?d=39498\&a=86652\&l=en.

National Board of Health and Welfare (Socialstyrelsen) (2008). Folkhälsa och sociala förhållanden 2008 [PublicHealth and Social Relationships 2008]. Lägesrapporter 2008

National Board of Health and Welfare (socialstyrelsen) (2010a) “Öppna jämförelser och utvärdering 2010. Psykiatrisk vard" National Board of Health and Welfare

National Board of Health and Welfare (Socialstyrelsen), SALAR (2010b), Quality and Efficiency in Swedish Health Care: Regional Comparisons 2010, Swedish National Board of Health and Welfare and Swedish Association of Local Authorities and Regions, Stockholm.

National Board of Health and Welfare (Socialstyrelsen) (2012) Health in Sweden: The National Public Health Report 2012, Scandinavian Journal of Public Health, December 2012; 40

National Board of Health and Welfare (Socialstyrelsen) (2013), "Folkhälsan i Sverige

Årsrapport 2013" (Public Health in Sweden, Annual Report 2013), National Board of Health and Welfare, 2013.

Nilsson T, Wallinius M, Gustavson C, Anckarsäter H, Kerekes N (2011), "Violent Recidivism: A LongTime Follow-Up Study of Mentally Disordered Offenders", PLoS ONE, Vol. 6, Iss. 10, p.1.

Nordic Council of Ministers (2011) "Strengthening mental health in the Norden - suggestions for initiatives for promotion of the exchange of knowledge and experience", report by the Nordic Expert Group on Mental Health 2009-2010, TemaNord 2011:514.

OECD (2012a), Sick on the Job?: Myths and Realities about Mental Health and Work, OECD Publishing. http://dx.doi.org/10.1787/9789264124523-1-en.

OECD (2012b) Health at a Glance: Europe 2012. http://dx.doi.org/10.1787/9789264183896-en

OECD (2013a), OECD Health Statistics 2013, OECD Publishing, Paris, http://dx.doi.org/10.1787/healthdata-en.

OECD (2013b), Mental Health and Work: Sweden, OECD Publishing. http://dx.doi.org/ 10.1787/9789264188730-en. .

OECD (2014a), Making Mental Health Count: The Social and Economic Costs of Neglecting Mental Health Care, OECD Health Policy Studies, OECD Publishing.

Oomen, Ber (ed.) (2007), Mental Health in Europe: the Contribution of Psychiatric Nursing Practice and Science, HORATIO - European Psychiatric Nurses, Amsterdam.

SALAR (2009), SALAR position paper on mental health, children and young people, The Swedish Association of Local Authorities and Regions 
SALAR (2011a) "Statistik Om Hälso- Och Sjukvård Samt Regional Utveckling 2010. Verksamhet Och Ekonomi I Landsting Och Regioner" Sveriges Kommuner och Landsting, 2011

SALAR (2011b) "Jämförelse Av Kostnader Och Verksamhet På Sjukhuskliniker 2010. Jämförelse Med Hjälp Av Totalkostnadsbokslut Och Patientuppgifter” Sveriges Kommuner och Landsting, 2011

Silfverhielm,H. \& Kamis-Gould, E. (2000). The Swedish mental health system. Past, present, and future.International Journal of Law and Psychiatry. May-Aug;23(3-4):293-307.

Stefansson, C-G (2006) "Chapter 5.5: Major public health problems: mental ill-health" Scandinavian journal of public health 2006; 34; 87.

Street, Andrew et al. (2007), Introducing Activity-Based Financing: A Review of Experience in Australia, Denmark, Norway and Sweden, Centre for Health Economics Research Paper 30, University of York.

Tuori, T., Gissler, M., Wahlbeck, K., and the Nordic reference group (2007) "Mental health in the Nordic Countries. In: NOMESCO: Health Statistics in the Nordic Countries 2005, pages 149-211" Nomesco, Nordic Medico-Statistical Committee 80. Copenhagen 


\section{USEFUL WEBSITE LINKS}

Handisam (2011). Hjarnkoll. Available at: http://www.hjarnkoll.se/In-English/

Nordic Council of Ministers (2011). Strengthening mental health in the Nordic countries - suggestions for initiatives for promotion of the exchange of knowledge and experience. Available at : http://www.norden.org/en/publications/publikationer/2011-514

OECD (2014b). The Rehabilitation Guarantee. Available at: http://www.oecd.org/els/emp/2\%20Sweden\%20-\%20The\%20Rehabilitation\%20Guarantee.pdf

Regeringskansliet. (2012). PRIO psykisk ohälsa - plan för riktade insatser inom området psykisk ohälsa 2012-2016 Available at: http://www.regeringen.se/content/1/c6/19/37/97/644e4dfe.pdf

Statistics Sweden (2012), Summary of population statistics 1960-2012;, Available at: www.scb.se/Pages/TableAndChart 26041.aspx

Statistics Sweden (2014). Statistiska Centralbyran. Available at: http://www.scb.se/default__2154.aspx

Socialstylrelsen (2007). Folkhälsa och olkhälsa och sociala förhållanden. Available at : http://www.socialstyrelsen.se/Lists/Artikelkatalog/Attachments/8865/2008-131-8_20081318_rev1.pdf

Socialstylrelsen (2014). National Guidelines. Available at: http://www.socialstyrelsen.se/nationalguidelines

Swedish Work Environment Authority (2014), "The Work Environment Act - with commentary as worded on $1^{\text {st }}$ August 2011", Available at: http://www.av.se/inenglish/lawandjustice/workact/index.aspx.

WHO. (2011). Mental Health Atlas Available at: http://apps.who.int/iris/bitstream/10665/44697/1/9799241564359_eng.pdf 


\section{OECD HEALTH WORKING PAPERS}

A full list of the papers in this series can be found on the OECD website: http://www.oecd.org/els/health-systems/health-workingpapers.htm

No. 81 MENTAL HEALTH ANALYSIS PROFILES (MhAPs) England (2015) Emily Hewlett and Kierran Horner

No. 80 ASSESSING THE IMPACTS OF ALCOHOL POLICIES (2015) Michele Cecchini, Marion Devaux, Franco Sassi

No. 79 ALCOHOL CONSUMPTION AND HARMFUL DRINKING: TRENDS AND SOCIAL DISPARITIES ACROSS OECD COUNTRIES (2015) Marion Devaux and Franco Sassi

No. 78 TAPERING PAYMENTS IN HOSPITALS - EXPERIENCES IN OECD COUNTRIES (2015) Grégoire de Lagasnerie, Valérie Paris, Michael Mueller, Ankit Kumar

No. 77 WAGE-SETTING IN THE HOSPITAL SECTOR (2014) James Buchan, Ankit Kumar, Michael Schoenstein

No. 76 HEALTH, AUSTERITY AND ECONOMIC CRISIS: ASSESSING THE SHORT-TERM IMPACT IN OECD COUNTRIES (2014) Kees van Gool and Mark Pearson

No. 75 COMPARING HOSPITAL AND HEALTH PRICES AND VOLUMES INTERNATIONALLY (2014) Francette Koechlin, Paul Konijn, Luca Lorenzoni, Paul Schreyer

No. 74 MENTAL HEALTH ANALYSIS PROFILES (MhAPS) Scotland (2014) Alessia Forti

No. 73 MENTAL HEALTH ANALYSIS PROFILES (MhAPs) Netherlands (2014) Alessia Forti, Chris Nas, Alex van Geldrop, Gedrien Franx, Ionela Petrea, Ype van Strien, Patrick Jeurissen

No. 72 MENTAL HEALTH ANALYSIS PROFILES (MhAPs) Finland (2014) Pauliina Patana

No. 71 MENTAL HEALTH ANALYSIS PROFILES (MhAPs) Italy (2014) Alessia Forti

No. 70 PRICING AND COMPETITION IN SPECIALIST MEDICAL SERVICES - AN OVERVIEW FOR SOUTH AFRICA (2014) Ankit Kumar, Grégoire de Lagasnerie, Frederica Maiorano, Alessia Forti

No. 69 GEOGRAPHIC IMBALANCES IN DOCTOR SUPPLY AND POLICY RESPONSES (2014) Tomoko Ono, Michael Schoenstein, James Buchan

No. 68 HEALTH SPENDING CONTINUES TO STAGNATE IN MANY OECD COUNTRIES (2014) David Morgan and Roberto Astolfi

No. 67 MEASURING AND COMPARING WAITING TIMES IN OECD COUNTRIES (2013) Luigi Siciliani, Valerie Moran and Michael Borowitz

No. 66 THE ROLE OF FISCAL POLICIES IN HEALTH PROMOTION (2013) Franco Sassi

No. 65 is now Health Working Paper no. 79. 
No. 64 MANAGING HOSPITAL VOLUMES: GERMANY AND EXPERIENCES FROM OECD COUNTRIES (2013) Michael Schoenstein and Ankit Kumar

No. 63 VALUE IN PHARMACEUTICAL PRICING (2013) Valérie Paris, Annalisa Belloni

No. 62 HEALTH WORKFORCE PLANNING IN OECD COUNTRIES: A REVIEW OF 26 PROJECTION MODELS FROM 18 COUNTRIES (2013) Tomoko Ono, Gaetan Lafortune and Michael Schoenstein

No. 61 INTERNATIONAL VARIATIONS IN A SELECTED NUMBER OF SURGICAL PROCEDURES (2013) Klim McPherson, Giorgia Gon, Maggie Scott

No. 60 HEALTH SPENDING GROWTH AT ZERO: WHICH COUNTRIES, WHICH SECTORS ARE MOST AFFECTED? (2013) David Morgan and Roberto Astolfi

No. 59 A COMPARATIVE ANALYSIS OF HEALTH FORECASTING METHODS (2012) Roberto Astolfi, Luca Lorenzoni, Jillian Oderkirk

No. 58 INCOME-RELATED INEQUALITIES IN HEALTH SERVICE UTILISATION IN 19 OECD COUNTRIES, 2008-09 (2012) Marion Devaux and Michael de Looper

No. 57 THE IMPACT OF PAY INCREASES ON NURSES' LABOUR MARKET: A REVIEW OF EVIDENCE FROM FOUR OECD COUNTRIES (2011) James Buchan and Steven Black

No. 56 DESCRIPTION OF ALTERNATIVE APPROACHES TO MEASURE AND PLACE A VALUE ON HOSPITAL PRODUCTS IN SEVEN OECD COUNTRIES (2011) Luca Lorenzoni and Mark Pearson

No. 55 MORTALITY AMENABLE TO HEALTH CARE IN 31 OECD COUNTRIES: ESTIMATES AND METHODOLOGICAL ISSUES (2011) Juan G. Gay, Valerie Paris, Marion Devaux, Michael de Looper

No. 54 NURSES IN ADVANCED ROLES: A DESCRIPTION AND EVALUATION OF EXPERIENCES IN 12 DEVELOPED COUNTRIES (2010) Marie-Laure Delamaire and Gaetan Lafortune

No. 53 COMPARING PRICE LEVELS OF HOSPITAL SERVICE ACROSS COUNTRIES: RESULTS OF A PILOT STUDY (2010) Luca Lorenzoni

No. 52 GUIDELINES FOR IMPROVING THE COMPARABILITY AND AVAILABILITY OF PRIVATE HEALTH EXPENDITURES UNDER THE SYSTEM OF HEALTH ACCOUNTS FRAMEWORK (2010) Ravi P. Rannan-Eliya and Luca Lorenzoni

No. 51 EFFECTIVE WAYS TO REALISE POLICY REFORMS IN HEALTH SYSTEMS (2010) Jeremy Hurst

No. 50 HEALTH SYSTEMS INSTITUTIONAL CHARACTERISTICS A SURVEY OF 29 OECD COUNTRIES (2010) Valerie Paris, Marion Devaux and Lihan Wei

No. 49 THE CHALLENGE OF FINANCING HEALTH CARE IN THE CURRENT CRISIS (2010) Peter Scherer, Marion Devaux 


\section{RECENT RELATED OECD PUBLICATIONS}

ADDRESSING DEMENTIA - THE OECD RESPONSE (2015)

CARDIOVASCULAR DISEASE AND DIABETES - POLICIES FOR BETTER HEALTH AND QUALITY OF CARE (2015)

DEMENTIA RESEARCH AND CARE: CAN BIG DATA HELP? (2015)

FIT MIND, FIT JOB - FROM EVIDENCE TO PRACTICE IN MENTAL HEALTH AND WORK (2015)

TACKLING HARMFUL ALCOHOL USE - ECONOMICS AND PUBLIC HEALTH POLICY (2015)

MAKING MENTAL HEALTH COUNT: THE SOCIAL AND ECONOMIC COSTS OF NEGLECTING MENTAL HEALTH CARE (2014)

HEALTH AT A GLANCE: EUROPE (2014)

HEALTH AT A GLANCE: ASIA/PACIFIC (2014)

OECD HEALTH STATISTICS 2014 (Database available from http://www.oecd.org/health/healthdata

GEOGRAPHIC VARIATIONS IN HEALTH CARE: WHAT DO WE KNOW AND WHAT CAN BE DONE TO

IMPROVE HEALTH SYSTEM PERFORMANCE? (2014)

PAYING FOR PERFORMANCE IN HEALTH CARE: IMPLICATIONS FOR HEALTH SYSTEM PERFORMANCE AND ACCOUNTABILITY (2014)

OBESITY HEALTH UPDATE (2014)

http://www.oecd.org/els/health-systems/Obesity-Update-2014.pdf (electronic format only)

OECD REVIEWS OF HEALTH CARE QUALITY - ITALY (2015)

OECD REVIEWS OF HEALTH CARE QUALITY - PORTUGAL (2015)

OECD REVIEWS OF HEALTH CARE QUALITY - CZECH REPUBLIC (2014)

OECD REVIEWS OF HEALTH CARE QUALITY - NORWAY (2014)

OECD REVIEWS OF HEALTH CARE QUALITY - TURKEY (2014)

OECD REVIEWS OF HEALTH CARE QUALITY - DENMARK (2013)

OECD REVIEWS OF HEALTH CARE QUALITY - SWEDEN (2013)

CANCER CARE - ASSURING QUALITY TO IMPROVE SURVIVAL (2013)

ICTS AND THE HEALTH SECTOR -TOWARDS SMARTER HEALTH AND WELLNESS MODELS (2013)

A GOOD LIFE IN OLD AGE? MONITORING AND IMPROVING QUALITY IN LONG-TERM CARE (2013)

STRENGTHENING HEALTH INFORMATION INFRASTRUCTURE FOR HEALTH CARE QUALITY GOVERNANCE (2013)

WAITING TIME POLICIES IN THE HEALTH SECTOR, WHAT WORKS? (2013)

HEALTH AT A GLANCE (2013): OECD INDICATORS (2013)

See http://www.oecd.org/health/healthataglance for more information

For a full list, consult the OECD On-Line Bookstore at www.oecd.org, or write for a free written catalogue to the following address:

OECD Publications Service, 2, rue André-Pascal, 75775 PARIS CEDEX 16 or to the OECD Distributor in your country 